\title{
Evolution of Fe Bearing Intermetallics During DC Casting and Homogenization of an Al-Mg-Si Al Alloy
}

\author{
S. KUMAR, P.S. GRANT, and K.A.Q. O'REILLY
}

The evolution of iron (Fe) bearing intermetallics (Fe-IMCs) during direct chill casting and homogenization of a grain-refined 6063 aluminum-magnesium-silicon (Al-Mg-Si) alloy has been studied. The as-cast and homogenized microstructure contained Fe-IMCs at the grain boundaries and within $\mathrm{Al}$ grains. The primary $\alpha$-Al grain size, $\alpha$-Al dendritic arm spacing, IMC particle size, and IMC three-dimensional (3D) inter-connectivity increased from the edge to the center of the as-cast billet; both $\alpha_{\mathrm{c}}$-AlFeSi and $\beta$-AlFeSi Fe-IMCs were identified, and overall $\alpha_{\mathrm{c}}$-AlFeSi was predominant. For the first time in industrial billets, the different Fe-rich IMCs have been characterized into types based on their 3D chemistry and morphology. Additionally, the role of $\beta$-AlFeSi in nucleating $\mathrm{Mg}_{2} \mathrm{Si}$ particles has been identified. After homogenization, $\alpha_{\mathrm{c}}$-AlFeSi predominated across the entire billet cross section, with marked changes in the 3D morphology and strong reductions in inter-connectivity, both supporting a recovery in alloy ductility.

DOI: $10.1007 / \mathrm{s} 11661-016-3451-5$

(C) The Author(s) 2016. This article is published with open access at Springerlink.com

\section{INTRODUCTION}

DUE to their high strength and good formability, AA6xxx Al alloys have found widespread applications as structural materials in the transport and building industries. ${ }^{[1]}$ The alloys are direct chill (DC) cast in billet form suitable for subsequent extrusion. Due to the non-equilibrium solidification conditions in DC casting, most of the solute elements (in this system, $\mathrm{Fe}, \mathrm{Si}$, and $\mathrm{Mg}$ ) segregate into the inter-dendritic regions and grain boundaries of the primary $\alpha-A 1 .{ }^{[2]}$ This solute-rich liquid leads to the formation of the inter-dendritic secondary phases, such as Fe-rich intermetallic compounds (Fe-IMCs) and strengthening $\mathrm{Mg}_{2} \mathrm{Si}$ precipitates. ${ }^{[3,4]}$ Previous studies show that $\alpha_{\mathrm{c}}$-AlFeSi and $\beta$-AlFeSi are the two dominant Fe-IMCs in $6063 \mathrm{Al}$ alloys. ${ }^{[5-8]} 3 \mathrm{D}$ analysis of these Fe-IMCs after extraction from the primary $\alpha$-Al using an $\mathrm{Al}$ dissolution approach revealed that $\alpha_{\mathrm{c}}-\mathrm{Al}(\mathrm{FeMn}) \mathrm{Si}$ (from now referred to as $\alpha_{\mathrm{c}}-\mathrm{AlFeSi}$ ) had a dendritic-like morphology while $\beta$-AlFeSi had a plate-like morphology. ${ }^{[9]}$ Among these IMCs, it has been noted that $\beta$-AlFeSi in particular, because of its more planar geometry, reduced the ductility of an $\mathrm{Al}$ alloy $6063 .{ }^{[6]}$ Therefore, a post-cast homogenization heat treatment is used commercially to encourage transformation of $\beta$ to $\alpha$ to allow: (a) more reliable

S. KUMAR, Research Fellow, P.S. GRANT, Professor, and K.A.Q. OREILLY, Professor, are with the Department of Materials, The EPSRC Centre for Innovative Manufacturing in Liquid Metal Engineering, Parks Road, Oxford, OX1 3PH, UK. Contact e-mail: kumar.sundaram@materials.ox.ac.uk

Manuscript submitted October 8, 2015.

Article published online April 13, 2016 downstream deformation, typically by extrusion, (b) improved mechanical properties, especially toughness and elongation to failure, and (c) improved surface finish. ${ }^{[5,10-16]}$

Despite the apparent maturity of AA6xxx alloys, there is a significant on-going effort to optimize homogenization conditions in terms of properties, while also minimizing the homogenization time. Among the factors that govern the homogenization response, the initial cast microstructure and the alloy chemical composition play key roles. Therefore, in developing new solidification processing routes ${ }^{[15]}$ or advanced solidification technologies ${ }^{[17-20]}$ that seek to promote more favorable as-cast microstructures, it is important to understand better the link between microstructural evolution in casting and the subsequent homogenization response of the secondary phases. For example the cooling rate and solid/liquid growth velocity in DC casting significantly affect the proportions of $\alpha_{\mathrm{c}}$-AlFeSi and $\beta$-AlFeSi in the final microstructure. ${ }^{[8,10,21,22]}$ But, since the cooling rate and growth velocity vary from position to position in the billet during DC casting, ${ }^{[2,23]}$ the primary $\mathrm{Al}$ grain size and proportion of the Fe-IMCs and $\mathrm{Mg}_{2} \mathrm{Si}$ across the cross section of the billet also varies, which should be accounted for in homogenization heat treatment optimization. In this paper, we apply an IMC phase extraction technique, along with a series of other characterization methods, at different positions in a AA6xxx DC cast billet to track in detail changes in the Fe-rich IMC inter-connectivity, size, morphology, type, and proportion during homogenization. The spatial variation of as-cast microstructure is shown to play a significant role in homogenization response and the various types of IMCs and their formation and transformation are described in detail. 


\section{EXPERIMENTAL DETAILS}

The chemical composition of the grain refined (Al-5Ti-1B) DC cast, $\sim 180 \mathrm{~mm}$ diameter Al-Mg-Si billet is given in Table I, measured using a Spectrolab LAVFA05A spark analyser optical emission spectrometer. Consistent with industrial practice, the cast billet was homogenized at $853 \mathrm{~K}\left(580^{\circ} \mathrm{C}\right)$ for $\sim 5$ hours. The billet before and after homogenization was sectioned horizontally across a diameter at the billet mid-height for microstructural analysis. Samples for metallography were ground with $\mathrm{SiC}$ papers and then polished to $0.06 \mu \mathrm{m}$ colloidal silica finish. Samples were also anodized with Barkers reagent $\left[7 \mathrm{~mL} \mathrm{HBF}_{4}\right.$ (48 pct) and $93 \mathrm{~mL} \mathrm{H}_{2} \mathrm{O}$ ] for 60 seconds at $20 \mathrm{~V}$ and studied by light microscopy (Zeiss Axiophot2) under polarized light and dark field imaging conditions to assess the

Table I. Chemical Composition (in Weight Percent) of the AA6063 Al Alloy Used in This Study

\begin{tabular}{lcccccccr}
\hline Sample & $\mathrm{Mg}$ & $\mathrm{Si}$ & $\mathrm{Fe}$ & $\mathrm{Mn}$ & $\mathrm{Cu}$ & $\mathrm{Ti}$ & $\mathrm{B}$ & $\mathrm{Al}$ \\
\hline AA6063 & 0.45 & 0.49 & 0.19 & 0.07 & 0.01 & 0.015 & 0.001 & balance \\
\hline
\end{tabular}
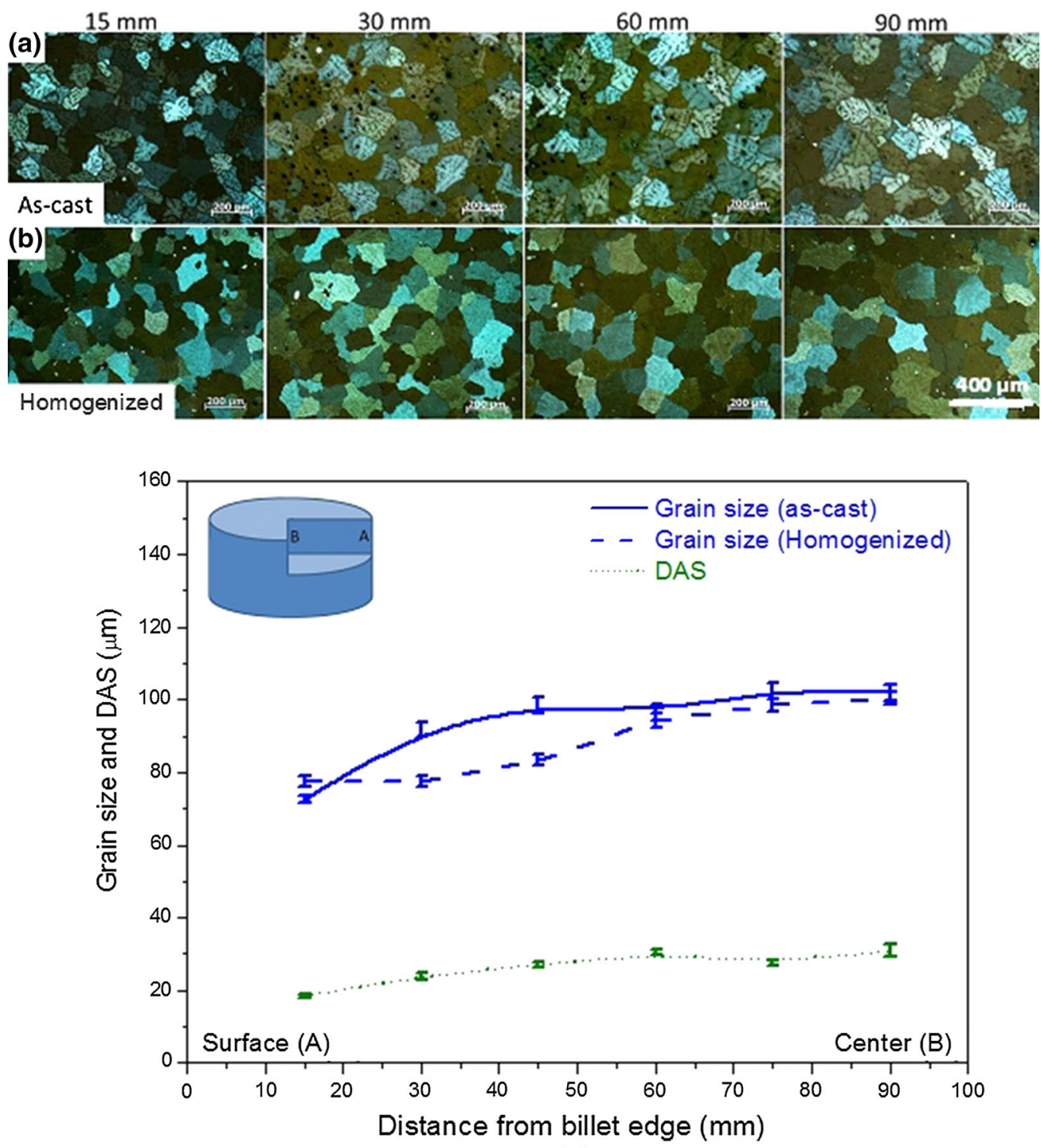

(c)

Fig. 1-Polarized light microscopy images showing the $\alpha$-Al grain size variation across the cross section of the $(a)$ as-cast and $(b)$ homogenized billets; $(c)$ the average grain size and DAS as a function of distance from the billet edge. The illustration inside (c) represents the position of the samples analyzed, where A and B represent the near surface and center of the billet. 


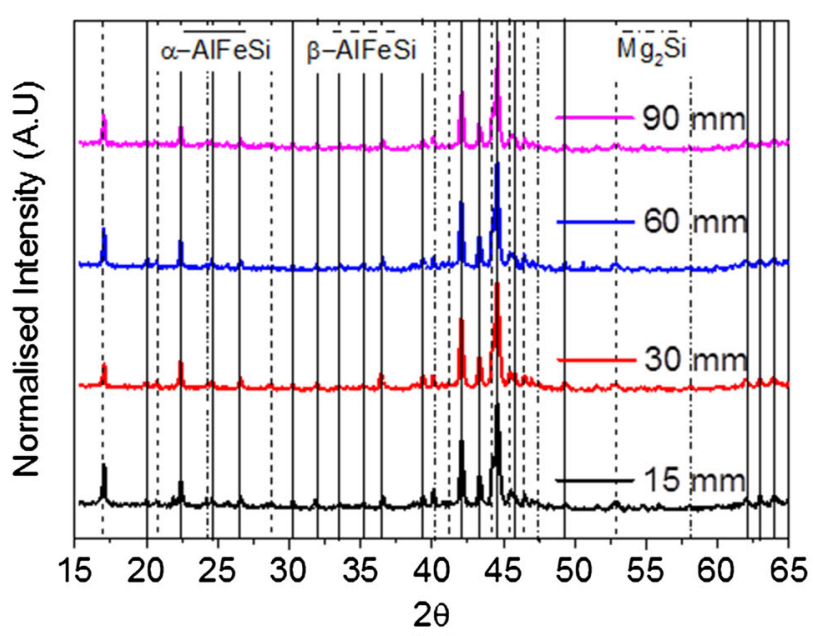

(a)

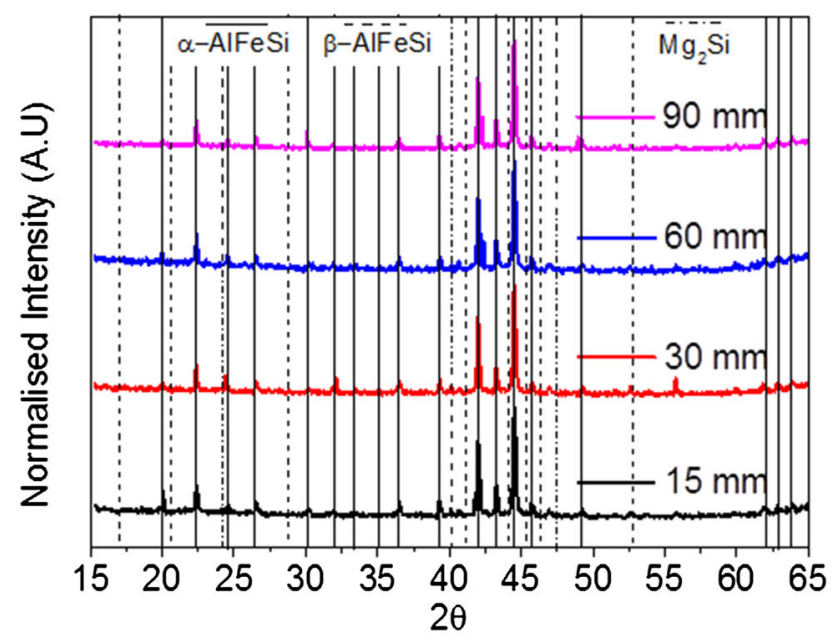

(b)

Fig. 2-XRD patterns from the extracted particles formed at different positions in the $(a)$ as-cast and $(b)$ homogenized billets. The cross section of the billet is illustrated in Figure 1(c) where 15, 30, 60, and $90 \mathrm{~mm}$ are the distances from the billet edge towards the billet center.

primary Al grain size and secondary phases. The mean linear intercept method was used to measure the primary $\mathrm{Al}$ grain size.

Scanning electron microscopy (SEM) was conducted in a JEOL 840A, and a JEOL 5510 equipped with a secondary electron (SE) detector, a backscattered electron (BSE) detector and an energy dispersive spectrometer (EDS). Second-phase particle size distributions were measured using Axio vision image analysis software on BSE images at $\times 500$ magnification and at least 1000 particles.

Intermetallic extraction apparatus (IEA) was used to extract the intermetallic particles from the as-cast and homogenized samples. IEA uses anhydrous boiling butan-1-ol (butanol) to dissolve the $\alpha$-Al matrix of the alloy while keeping the intermetallic phases intact. The intermetallics were then collected on a polytetrafluoroethylene (PTFE) filter membrane $(47 \mathrm{~mm}$ diameter,

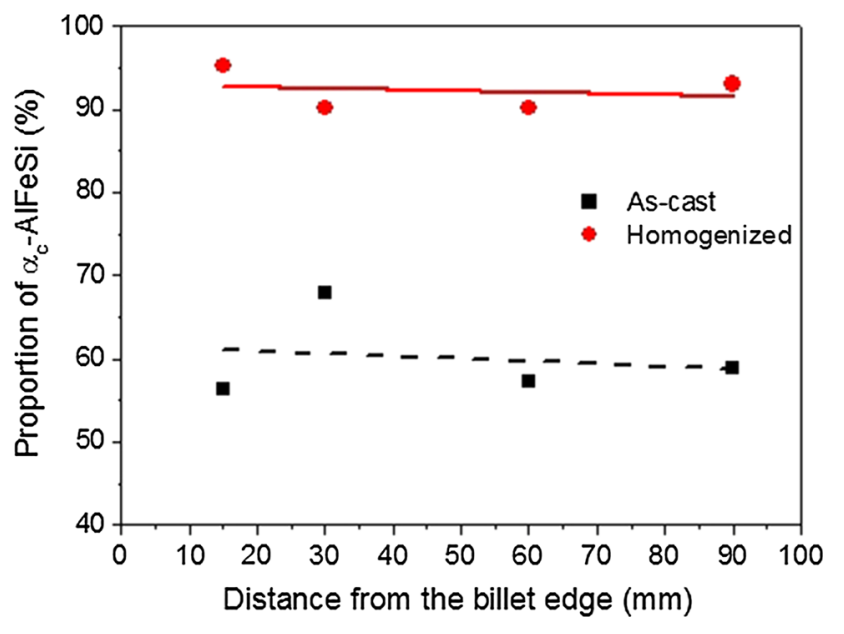

Fig. 3-Relative proportions of $\alpha_{\mathrm{c}}$-AlFeSi and $\beta$-AlFeSi formed at different positions in the as-cast and homogenized billets.

pore size of $0.2 \mu \mathrm{m})$. The phases were identified in a Philips $1700 \mathrm{X}$-ray diffractometer (XRD) operating with $\mathrm{Cu}-\mathrm{K}_{\alpha}(\lambda=1.54 \AA)$ radiation at $35 \mathrm{kV}, 50 \mathrm{~mA}$, and 0.05 deg step size. An in-house developed calibration procedure was used for determining the relative weight fractions of $\alpha_{\mathrm{c}}$-AlFeSi and $\beta$-AlFeSi from XRD data, more details of which can be found in references. ${ }^{[8,22,24]}$ The extracted particles were further analyzed using a high-resolution field emission gun (FEG) SEM (JEOL $840 \mathrm{~F})$. The approach used to measure the IMCs inter-connectivity, length of petals, and length of longest facet side of platelets of the extracted particles was detailed in previous work. ${ }^{[2]}$ MTDATA studio 5.10 software with NPL aluminum database V6.1 was used to predict phases as a function of temperature under various assumptions (see later).

\section{RESULTS}

\section{A. Primary $\alpha$-Al Grain Analysis}

The polarized light microscopy images in Figure 1(a) show the dendritic equiaxed morphology of $\alpha$-Al grains across the cast billet cross section. The grain size and dendrite arm spacing (DAS) increased from the near surface to the center of the cast billet (Figure 1(c)). This suggested a change in cooling rate along the billet cross section. The cooling rate can be estimated from ${ }^{[25]}$

$$
V=3.57 \times 10^{4} \mathrm{DAS}^{-2.56}
$$

where $V$ is the cooling rate, $\mathrm{Ks}^{-1}$. Using the observed DAS $(\mu \mathrm{m})$, the cooling rate at distance of $15,30,60$, and $90 \mathrm{~mm}$ from the billet edge towards the center was estimated as 20.2, 10.4, 5.7, and $5.4 \mathrm{Ks}^{-1}$, respectively, which showed good agreement with measured data. ${ }^{[23,26,27]}$ In general during DC casting, the liquid metal is delivered from the furnace to the water cooled ring mold by a launder. ${ }^{[23]}$ Once the melt comes in to contact with the mold it starts to solidify and forms a 

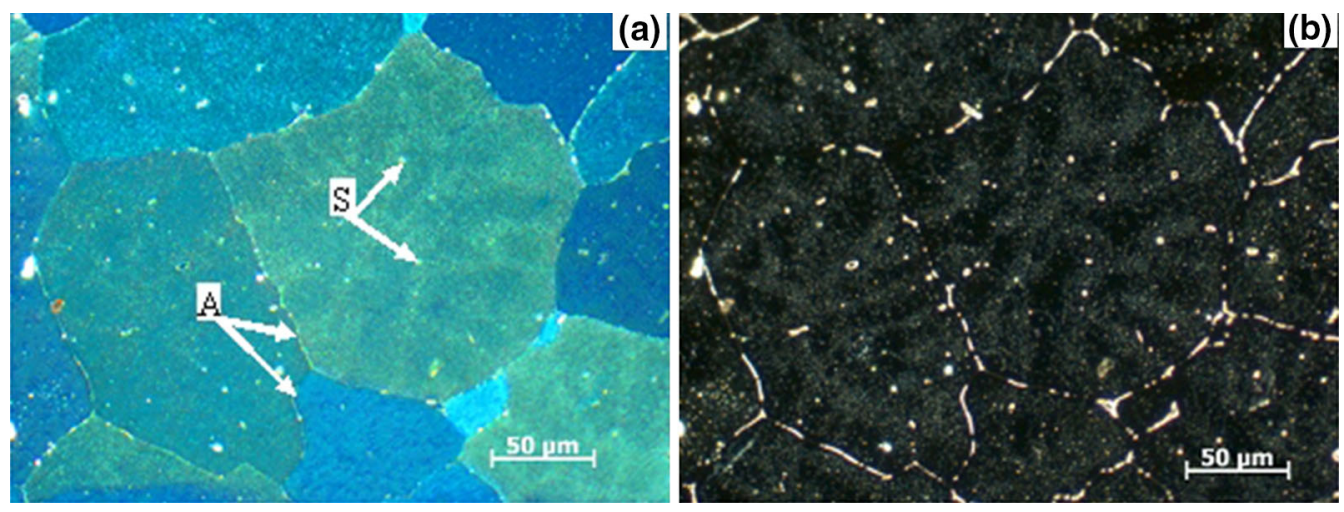

Fig. 4 - (a) Polarized and $(b)$ dark field light microscopy images of the microstructure in the center region of the homogenized billet, with secondary phases at the grain boundary (A) and within the $\mathrm{Al}$ grains (S). Fe-IMCs and $\mathrm{Mg}_{2} \mathrm{Si}$ are brighter in (b).

thin solid shell around the hot liquid. Further withdrawal of the base of the mold results in water directly coming into contact with the solidifying shell, and induces cooling rates of $20 \mathrm{Ks}^{-1}$ (near surface) to $1 \mathrm{Ks}^{-1}$ (billet center), ${ }^{[23]}$ similar those estimated here in this study. Because of the inevitably higher cooling rate at the billet surface, finer $\alpha$-Al grains and a smaller DAS resulted in this region, as shown in Figure 1.

After homogenization, the $\alpha$-Al grain morphology showed similar features to the as-cast structure (Figures 1(a) and (b)), but the DAS became difficult to quantify due to a reduction in inter-dendritic contrast. However, the grain size in the homogenized billet followed a similar trend with respect to the as-cast billet. All error bars in this manuscript indicate the standard deviation of the mean, unless stated.

\section{B. Secondary Phase Analysis}

\section{XRD analysis of extracted particles}

In order to evaluate the type and proportion of the secondary phases in these relatively dilute Al alloy systems, where secondary phase fractions are less than $3 \mathrm{wt}$ pct, it is most effective to extract the particles from the $\alpha$-Al matrix for various types of subsequent analyses. The XRD trace from the extracted particles in Figure 2 shows cubic $\alpha_{\mathrm{c}}-\mathrm{AlFeSi}\left(\alpha_{\mathrm{c}}-\mathrm{Al}(\mathrm{FeMn}) \mathrm{Si}\right)$, monoclinic $\beta$-AlFeSi, and cubic $\mathrm{Mg}_{2} \mathrm{Si}$ phases along the billet cross section, taken at distances of $15,30,60$, and $90 \mathrm{~mm}$ from the billet edge towards the center. Of the Fe-IMCs, $\alpha_{\mathrm{c}}$-AlFeSi showed the highest intensity peaks ( $\left.>50 \mathrm{pct}\right)$ in both as-cast (Figure 2(a)) and homogenized (Figure 2(b)) billets. Using calibrated standards ${ }^{[28]}$ to gain phase fractions, Figure 3 shows that in the as-cast billet, the proportion of $\alpha_{c}-\mathrm{AlFeSi}$ relative to $\beta$-AlFeSi was almost uniform across the radius. However after homogenization heat treatment, in all locations, the homogenized billet had a higher fraction ( $>90$ pct) of $\alpha_{\mathrm{c}}$-AlFeSi (i.e. less $\beta$-AlFeSi). The $\mathrm{Mg}_{2} \mathrm{Si}$ fraction was also lower in the homogenized billet. It is important to note that the pore size of the filter paper used to collect the extracted particles was $200 \mathrm{~nm}$ and only individual particles or clusters of particles bigger than the pore size will be present in the analysis.

\section{Metallography}

The homogenized billet showed secondary phase particles at the grain boundaries (A) and within Al grains (S) (Figure 4(a)). The particles (brighter in Figure 4(b)) at the grain boundaries had a higher aspect ratio then particles within the grains. The larger aspect ratio Fe-IMCs particles mostly had script-like (Figure 5(a)) and needle-like (Figure 5(b)) morphologies, and the smaller aspect ratio particles had a rosette-like (Figure 5(c)) morphology. Morphologies were similar in the as-cast billet ${ }^{[9,22]}$ and it was concluded that the script-like and needle-like Fe-IMC morphologies could be attributed to $\alpha_{c}-\mathrm{AlFeSi}$ and $\beta$-AlFeSi, respectively. ${ }^{[28,29]}$ The rosette-like $2 \mathrm{D}$ morphology was also attributed to $\alpha_{c}-\mathrm{AlFeSi}{ }^{\left[{ }^{[28]}\right.}$ However, Fe-IMC particles in the homogenized billet were smaller in size with a narrower size distribution when compared to the as-cast samples (Figure 6), and the equivalent particle size (the diameter of a circle with the same area as the projection area of the irregular shaped particle) increased towards the center in both the as-cast (Figure 6(a)) and homogenized billets (Figure 6(b)). The more spherical, minor fractions of particles within grains changed little after homogenization, and data from these particles are not included in these plots.

Grain boundary $\mathrm{Mg}_{2} \mathrm{Si}$ in the as-cast billet tended to be co-located with the needle-like Fe-IMCs (Figure 7(a)), whereas $\mathrm{Mg}_{2} \mathrm{Si}$ within $\alpha$-Al grains was mostly co-located with the rosette-like Fe-IMCs (Figure 7(b)). For example, the EDS line scan across the rosette-like region in Figure 7(c) showed $\mathrm{Mg}_{2} \mathrm{Si}$ and $\mathrm{Fe}-\mathrm{IMCs}$ together. There was also individual needle-like $\mathrm{Mg}_{2} \mathrm{Si}$ at the grain boundaries of the cast billet. However, the $\mathrm{Mg}_{2} \mathrm{Si}$ in the homogenized billet was coarser with an average equivalent particle size of $\mathrm{Mg}_{2} \mathrm{Si}$ at the center of the as-cast and homogenized billets of $1.6 \pm 0.1$ and $2.9 \pm 0.2 \mu \mathrm{m}$, respectively. In the homogenized billet, the $\mathrm{Mg}_{2} \mathrm{Si}$ mostly had rod-like and spherical-like morphologies at the grain boundaries. 


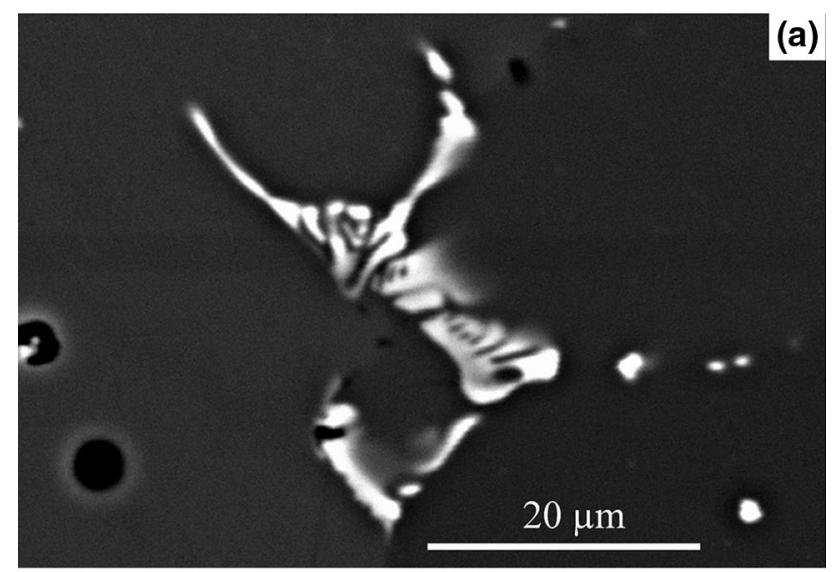

(b)
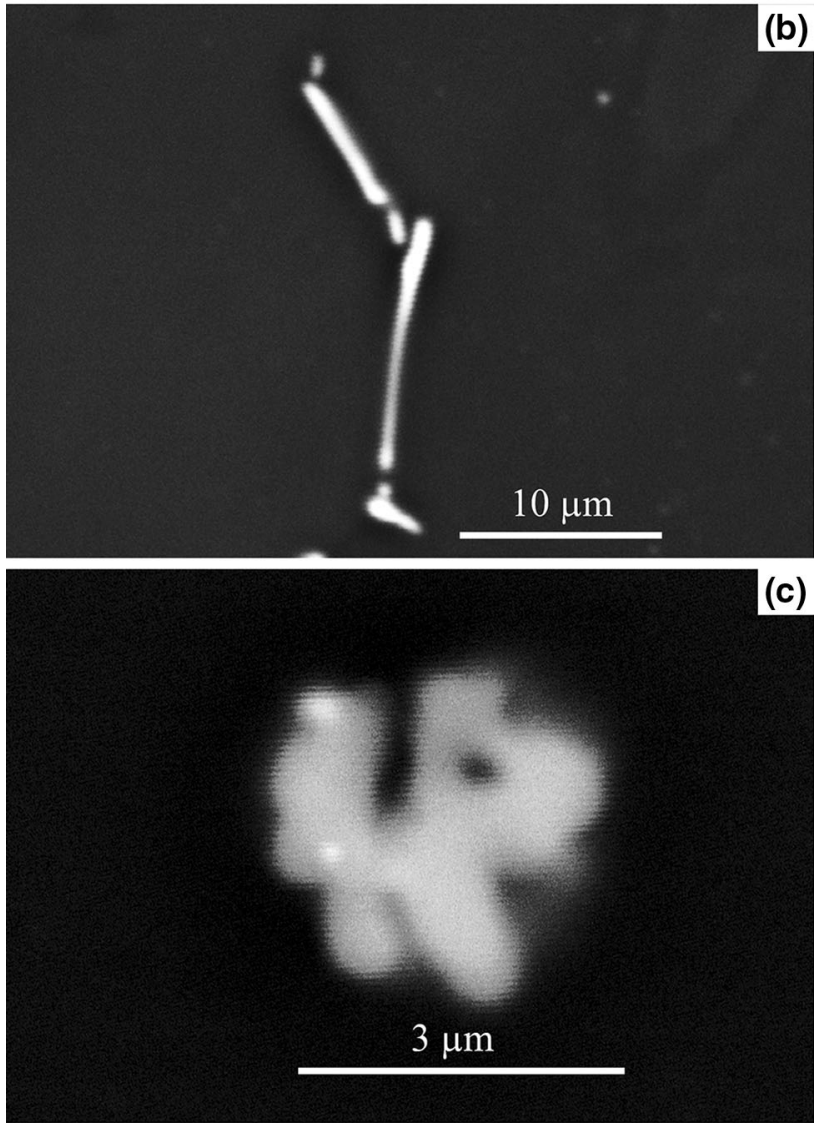

Fig. 5-BSE-SEM images of the 2D morphology of the different IMCs in the homogenized billet $90 \mathrm{~mm}$ from the billet edge towards the center, indicating (a) script-like, $(b)$ needle-like, and $(c)$ rosettelike particles.

\section{SEM analysis of extracted particles}

In order to understand better the nature (inter-connectivity and morphology) of the secondary phase particles that form during the solidification and homogenization of the DC billets, extracted particles were investigated. Critically this approach revealed that the grain boundary IMC particles in the as-cast billet were a network of highly inter-connected Fe-IMCs in 3D (Figure 8(a)), and the inter-connectivity (Figure 8(c)) increased towards the billet center. High magnification

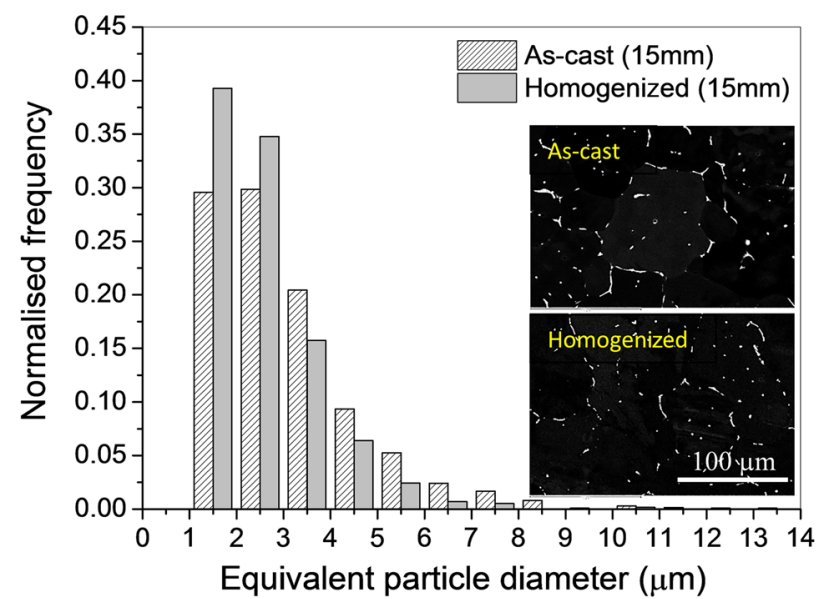

(a)

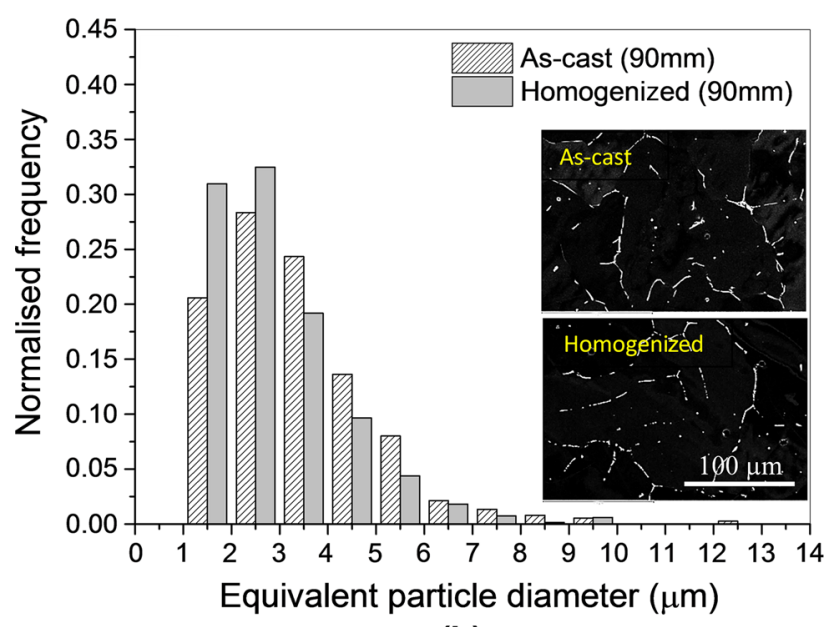

(b)

Fig. 6-The Fe-IMC equivalent particle diameter increased from $(a)$ $15 \mathrm{~mm}$ from the billet edge to (b) $90 \mathrm{~mm}$ from the billet edge for the as-cast and homogenized billets. Homogenization resulted in smaller particles with a narrower size distribution. Measurements were made from the BSE-SEM images of the metallography samples, shown as insets.

imaging revealed that the as-cast Fe-IMCs were mostly dendritic/petal-like $\alpha_{c}-\mathrm{AlFeSi}$ (Figure 9(a)), and platelet-like $\beta$-AlFeSi (Figure 9(b)), consistent with previous work. ${ }^{[9,22]}$ The length of the petals increased towards the billet center (Figure 10(a)), but there was little difference in the longest facet length of the platelets. Similar to the dendritic/petal-like particles, the platelet-like particles showed an ability to branch and adopt complex, extended 3D geometries, as well as appearing to nucleate other platelets (Figure 9(b)). Unusually, $\mathrm{Mg}_{2} \mathrm{Si}$ was resolved forming on the flat faces and facet-sides of the $\beta$-AlFeSi (Figure 11).

Based on this $\mathrm{Mg}_{2} \mathrm{Si}$ interaction with $\beta$-AlFeSi platelets, confirmed by the investigation of many such instances, the $\mathrm{Mg}_{2} \mathrm{Si} / \beta$ interaction was classified into three types. Type 1 was dendrite-like (Figure 11(a)), octahedral-like (Figure 11(b)), and cubic-like (Figure 11(c)) with $\mathrm{Mg}_{2} \mathrm{Si}$ on the basal face of the $\beta$-AlFeSi; Type 2 was seaweed-like $\mathrm{Mg}_{2} \mathrm{Si}$ on the facet-sides (Figure 11(d)); and Type 3 was fine 

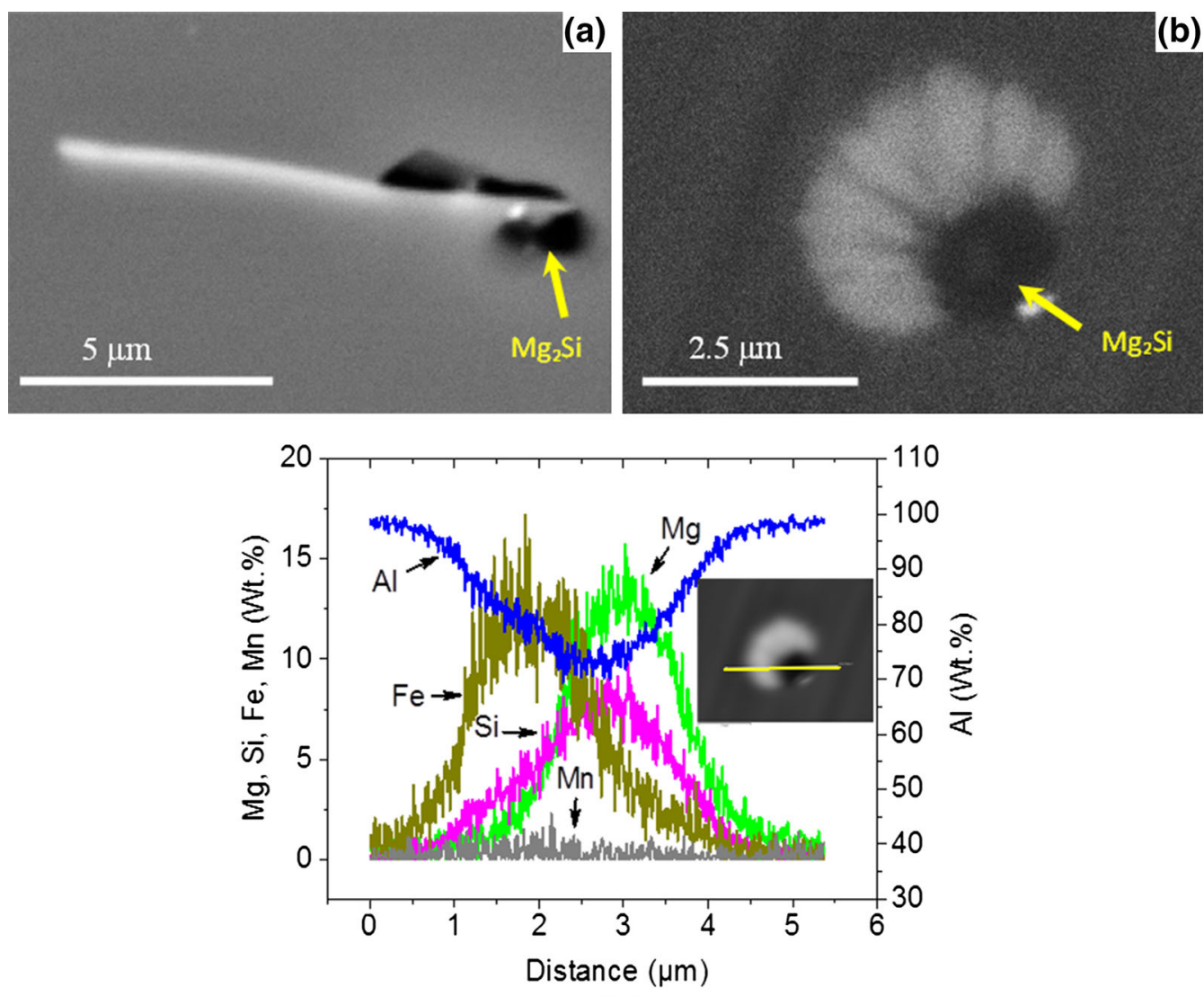

(c)

Fig. 7-BSE-SEM images from the as-cast billet showing $\mathrm{Mg}_{2} \mathrm{Si}$ (darker particle) associated with $(a$ ) needle-like and $(b)$ rosette-like Fe-IMCs (brighter particle). The EDS line scan in $(c)$ shows the composition variation along the rosette-like particle in (b).

needle-like particles on the basal face with two different directional alignments (Figure 11(e)).

In addition, there were discrete, spherical-like particles that were not connected with the inter-dendritic secondary phase network, which suggested that they were those secondary phases observed inside grains in the earlier 2D sections. These discrete spherical-like particles were $\sim 3 \mu \mathrm{m}$ in size (Figure 10(a)) and were either: (i) clusters of Fe-IMCs (Figure 12(a)), (ii) clusters of Si particles (Figure 12(b)), (iii) cubic-like $\mathrm{Mg}_{2} \mathrm{Si}$, or (iv) composite agglomerates of one or more of (i) to (iii). For example, Figure 12(c) shows a composite agglomerate of $\mathrm{Mg}_{2} \mathrm{Si}$ and Fe-IMCs. The $\mathrm{Mg}_{2} \mathrm{Si}$ with the rosette-like Fe-IMC in Figure 7(b) was revealed to have a more complex octagon-like morphology when viewed after extraction, as shown in Figure 12(c).

Interestingly, the inter-connectivity reduced significantly after homogenization in all locations (Figures 8(b) and (c)) and the billet center retained the longest inter-connectivity length (Figure $8(\mathrm{c})$ ). The previously inter-connected $\mathrm{Fe}-\mathrm{IMCs}$ fragmented during homogenization into discrete particles, as shown in Figure 8(b), of the form: (i) partly degraded dendritic-like $\alpha_{\mathrm{c}}$-AlFeSi in Figure 9(c); (ii) near cylindrical/ disk-like $\alpha_{c}-\mathrm{AlFeSi}$ in Figure 9(d); or (iii) spherical-like
$\alpha_{c}-\mathrm{AlFeSi}$ in Figure 9(e). The dendritic/petal-like Fe-IMCs in Figure 9(c) were similar to the as-cast particles in Figure 9(a), but were now partly dissolved at the corners and at the thin regions of the arms (indicated with arrows). The wrinkle patterns on the surface of as-cast petal-like Fe-IMC particles in Figure 9(a) were also now absent. The length of the partly degraded/ dissolved petals (Figure 10(b)) was similar to that in the as-cast billet (Figure 10(a)). It was difficult to resolve any needle- or platelet-like Fe-IMC particles after homogenization, but there was a notable increased incidence of disk-like particles, e.g., Figure 9(d), which suggested that larger platelet-like $\beta$-AlFeSi particles transformed into fine disk-like $\alpha_{\mathrm{c}}-\mathrm{AlFeSi}$, and in agreement with the XRD results in Figure 2(b). The disk-like Fe-IMC particles were mostly connected to at least two or three other disks. The average interconnected length was $\sim 20 \mu \mathrm{m}$ (Figure 10(b)).

The apparently large proportion of needle-like Fe-IMC particles in the 2D sections of the homogenized billet in Figure 5(b) was inconsistent with the XRD quantification of the extracted phases and SEM studies. This discrepancy was in part due to the perpendicular preferred orientation of the dendritic-like particles with respect to the sectioned plane that over emphasizes their 

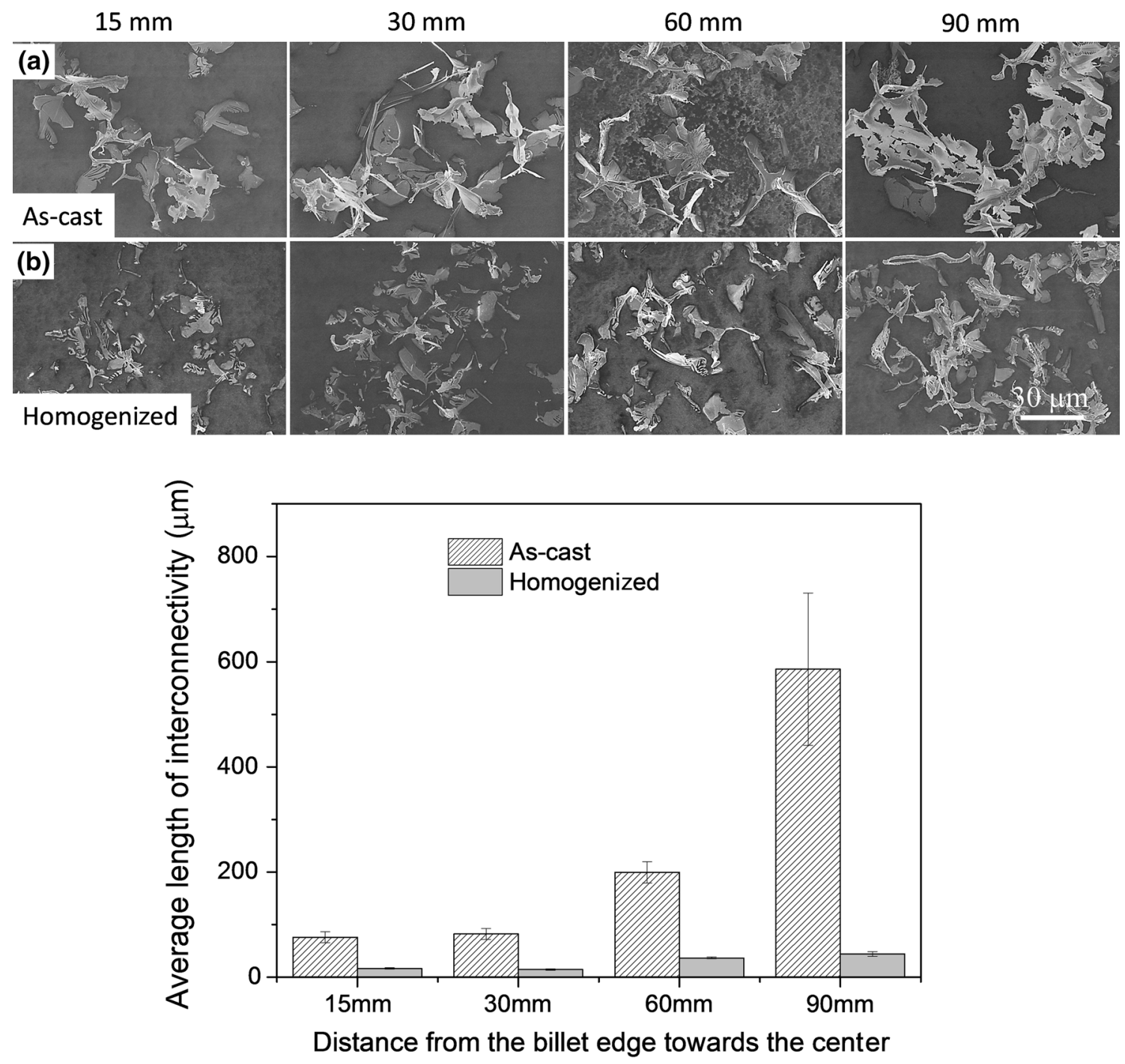

(c)

Fig. 8- SE FEG-SEM images of the IMCs extracted at different locations in the $(a)$ as-cast and $(b)$ homogenized billets; $(c)$ is the measured average length of the inter-connectivity for the IMCs at different positions.

proportion, even when a systematic and monotonic change in particle size distribution is measured (Figure 6). In other words, these 2D sections not only fail to convey the correct size and morphology of the extended IMCs, but since the particles are generally far from spherical, 2D sections can also lead to incorrect quantification of phase fractions using standard metallographic approaches.

In the homogenized billet and following extraction, the $\mathrm{Mg}_{2} \mathrm{Si}$ particles were mostly type 1 , cylinder-like in Figure 13(a) (arrow marked) and type 2, fine needle-like in Figure 13(b), lying predominantly in two alignments. The rosette-like Fe-IMCs in Figure 13(c) now presented with a central hole following homogenization, and are suggested to be originally of the type shown in Figures 7(b) and (c) and 12(c) but now with the central cluster of $\mathrm{Mg}_{2} \mathrm{Si}$ dissolved during homogenization.

\section{DISCUSSION}

\section{A. Evolution of IMCs During Solidification}

1. Solidification sequence and Fe-IMC phase selection

For the alloy composition used in the billets here, thermodynamic simulations of the phase fractions as a function of temperature using MTDATA software and the NPL aluminum database V6.1 were performed, which are shown in Figure 14, under conditions of equilibrium calculation (Figure 14(a)) and conditions of perfect elemental mixing in the liquid, but no diffusion in the solid (so called "Scheil" conditions) (Figure 14(b) and (c)). Figure 14(a) shows that the $\alpha$-Al is the first phase to form on solidification. Because in the experiments and conforming to industrial practice, a $\mathrm{TiB}_{2^{-}}$ based grain refiner was used, the primary $\mathrm{Al}$ manifested as equiaxed $\alpha$-Al grains across the billet section, and as 

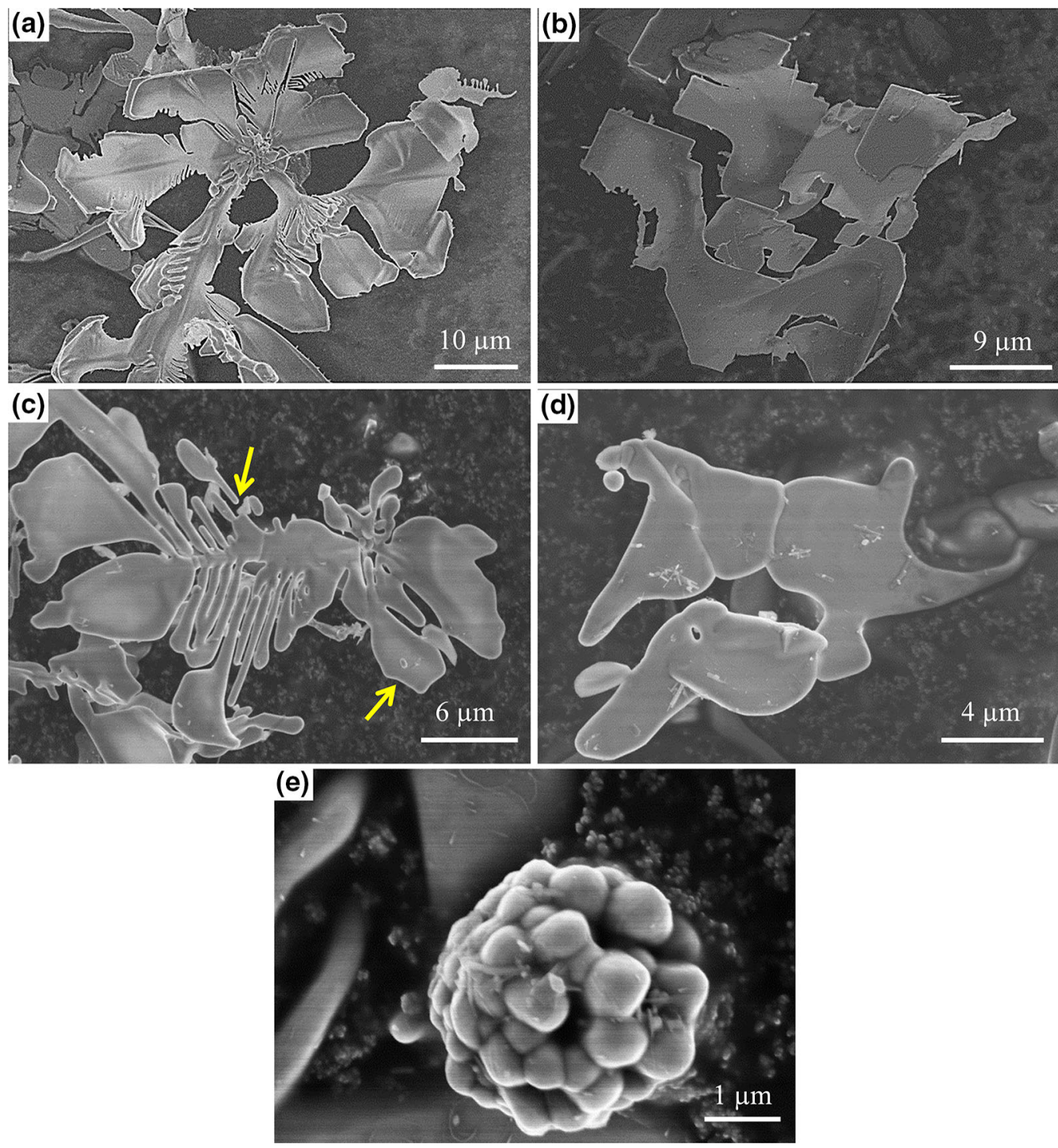

Fig. 9-SE FEG-SEM images of the extracted particles revealing $(a)$ dendrite-like, $(b)$ platelet-like, $(c)$ partially dissolved dendrite-like, $(d)$ disk-like, and $(e)$ rosette-like particles. Where (a through b) are from as-cast billet and (c through e) are from homogenized billet. Arrows indicate the partly dissolved regions.

is well known, the dendritic nature of the grains relates to the solute-induced instability of a planar interface during their growth. Figure 15(a) illustrates the nucleation and growth of primary $\alpha$-Al dendrites at the solidifying front of a solidifying billet during DC casting.

Due to the different diffusion rates of the solute elements ( $\mathrm{Fe}, \mathrm{Si}, \mathrm{Mg}, \mathrm{Mn}$ ) in the liquid and solid $\mathrm{Al}$, and their differing but generally limited solid solubility limits in $\mathrm{Al}$ (especially $\mathrm{Fe}$ and $\mathrm{Si}$ ), solute elements tended to accumulate at the growing solid-liquid interface, and within the shrinking liquid fraction in inter-dendritic regions. The resulting solute-rich liquid may then undergo different variant and invariant reactions as the temperature decreases further, the nature of which depends critically on the local composition, cooling rate and nucleation density environment. This scenario is also shown schematically in Figure 15(a) where a Fe-IMC eutectic front develops late in the solidification sequence. Here, "local" refers to the size of the inter-dendritic regions and the length scale of their inter-connectivity. The resulting secondary phases were clearly resolved in the anodized microstructures and extracted particles (e.g. Figures 1 and 8).

Since DC casting provides a range of cooling rates depending on casting conditions and position in the billet, the resulting secondary phases may be thermodynamically stable i.e., predictable by phase fraction calculations with appropriate data, or metastable i.e., unpredictable by calculation, or at least only with some manipulation, as in the case for $\beta$-AlFeSi here, which is generally considered metastable although frequently observed in practice. Under the assumptions in Figure 14(b), the formation of $\mathrm{Al}_{13} \mathrm{Fe}_{4}, \alpha-\mathrm{AlFeSi}$, 


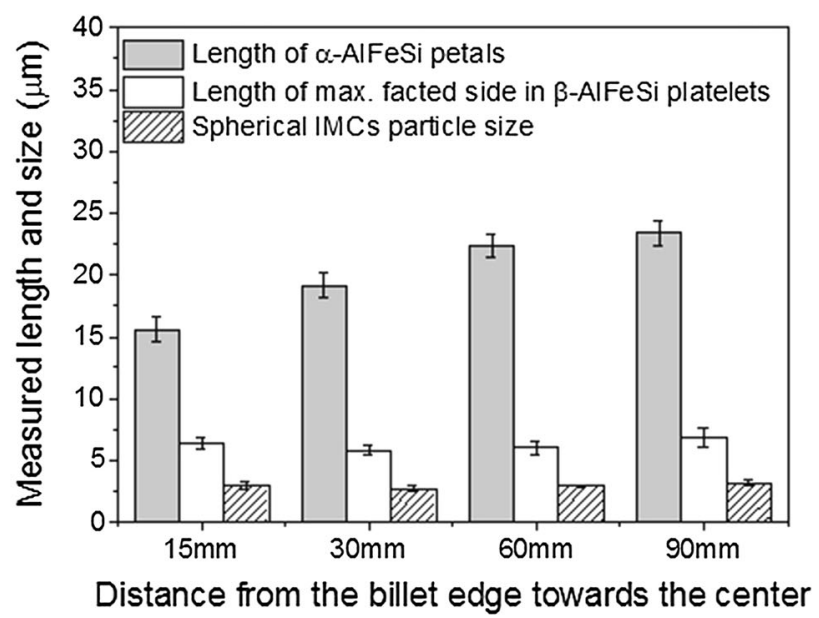

(a)

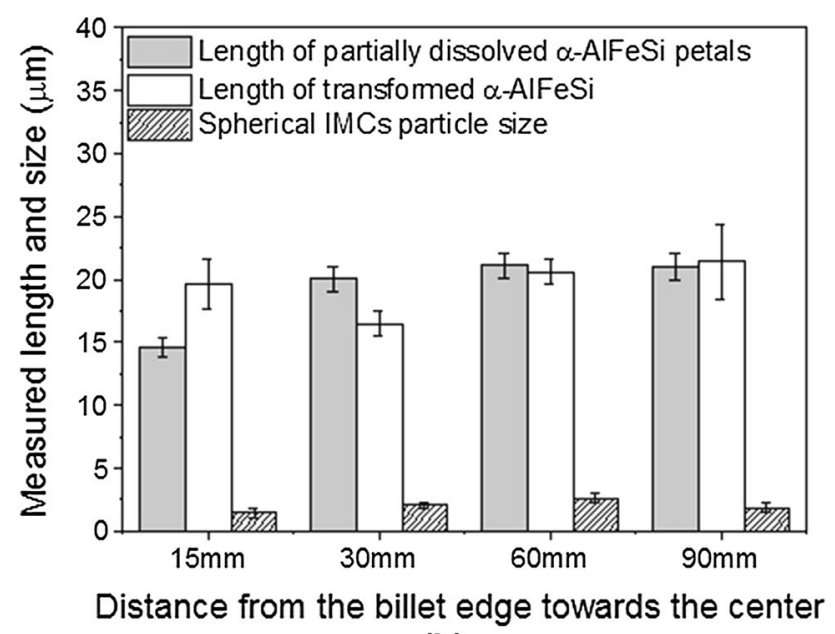

(b)

Fig. 10-Length and size of IMC particles extracted at different positions from the $(a)$ as-cast and $(b)$ homogenized billets.

$\beta$-AlFeSi, $\alpha$-AlMnSi, $\mathrm{Mg}_{2} \mathrm{Si}$, and $\mathrm{Si}$ in sequence from the liquid during solidification were predicted, and in general the following possible variant and invariant solidification reactions have been suggested for $6 \mathrm{xxx}$ series Al alloys: ${ }^{[7,30-33]}$

$$
\begin{gathered}
\mathrm{L} \rightarrow \mathrm{Al}_{13} \mathrm{Fe}_{4}+\alpha-\mathrm{Al} \\
\mathrm{L}+\mathrm{Al}_{13} \mathrm{Fe}_{4} \rightarrow \alpha-\mathrm{AlFeSi}+\alpha-\mathrm{Al} \\
\mathrm{L} \rightarrow \alpha-\mathrm{AlFeSi}+\alpha-\mathrm{Al} \\
\mathrm{L}+\alpha-\mathrm{AlFeSi} \rightarrow \beta-\mathrm{AlFeSi}+\alpha-\mathrm{Al} \\
\mathrm{L}+\mathrm{Al}_{13} \mathrm{Fe}_{4} \rightarrow \beta-\mathrm{AlFeSi}+\alpha-\mathrm{Al} \\
\mathrm{L} \rightarrow \beta-\mathrm{AlFeSi} \rightarrow \alpha-\mathrm{Al} \\
\mathrm{L} \rightarrow \mathrm{Mg}_{2} \mathrm{Si}+\alpha-\mathrm{Al}
\end{gathered}
$$

$$
\begin{gathered}
\mathrm{L} \rightarrow \beta-\mathrm{AlFeSi}+\mathrm{Mg}_{2} \mathrm{Si}+\mathrm{Si}+\alpha-\mathrm{Al} \\
\mathrm{L} \rightarrow \mathrm{Mg}_{2} \mathrm{Si} \\
\mathrm{L} \rightarrow \alpha-\mathrm{AlMnSi}+\mathrm{Si}+\alpha-\mathrm{Al}
\end{gathered}
$$

The XRD analyses (Figure 2) and SEM analyses (Figures 6 through 12) confirmed the presence of $\alpha_{\mathrm{c}}$-AlFeSi, $\beta$-AlFeSi, and $\mathrm{Mg}_{2} \mathrm{Si}$. The largest discrepancy between modeling (Figure 14(b)) and the possible phases described by reactions 1 to 9 was the absence of $\mathrm{Al}_{13} \mathrm{Fe}_{4}$ (Eq. [1]) in experiment and this may arise either because soon after formation it was rapidly transformed to $\alpha$ - or $\beta$-AlFeSi (for which Figure 14 offers little support), or more likely that it was comparatively difficult to nucleate and grow $\mathrm{Al}_{13} \mathrm{Fe}_{4}$ at the required rate so that once $\alpha$ - or $\beta$-AlFeSi were formed, it was kinetically preferred for the residual Fe-rich liquid to be transformed as further $\alpha$ - or $\beta$-AlFeSi, rather than through the nucleation of a new phase. ${ }^{[8,33]}$ This agrees well with the modeling when the Scheil calculations were performed without the $\mathrm{Al}_{13} \mathrm{Fe}_{4}$ phase (Figure 14(c)). The absence of the predicted much smaller fraction of $\alpha$-AlMnSi (Eq. [10]) was possibly due its transformation to other phases, its low fraction, or again due to its suppression by more kinetically favorable solidification reactions. Although the SEM investigations revealed discrete Si particles (Figure 12(b)), the absence of Si in XRD analysis was probably because the volume fraction was too low for detection. It should also be noted that by comparison with previous work in, ${ }^{[18]}$ the present work suggests that thermodynamic predictions of phase fractions only indicate formation of $\beta$-AlFeSi, consistent with experiment, when non-equilibrium (no solid diffusion) assumptions were used.

From the as-cast and extracted morphology and length scale of $\alpha_{\mathrm{c}}$-AlFeSi, it was suggested that most formed directly from the liquid via eutectic reaction (3), rather than peritectic reaction (2), because the peritectic reaction implies $\alpha_{c}-\mathrm{AlFeSi}$ forming around $\mathrm{Al}_{13} \mathrm{Fe}_{4}$ or a composite of both, for which no XRD or SEM evidence was found. By similar consideration, $\beta$-AlFeSi is suggested to form directly from the liquid through eutectic reactions (6) and/or (8).

The selection of either $\alpha_{\mathrm{c}}$-AlFeSi or $\beta$-AlFeSi from the cooling inter-dendritic liquid will be governed by their relative ease of nucleation and growth. ${ }^{[2]}$ For nucleation, the phase with the higher nucleation temperature (small nucleation undercooling) should be preferred initially while the phase with the higher stable growth temperature (higher growth velocity) will be preferred subsequently, if its nucleation is possible. The competition between these two criteria for each phase within the local inter-dendritic environment will determine which phase(s) will be seen in practice. However, as shown in Figures 2 and 3 in particular, at all places in the billet at the meso-scale, both $\alpha_{\mathrm{c}}$-AlFeSi and $\beta$-AlFeSi form. However, at the micro-scale $\alpha_{\mathrm{c}}$-AlFeSi and $\beta$-AlFeSi did not form together within any particular inter-dendritic (grain boundary) 

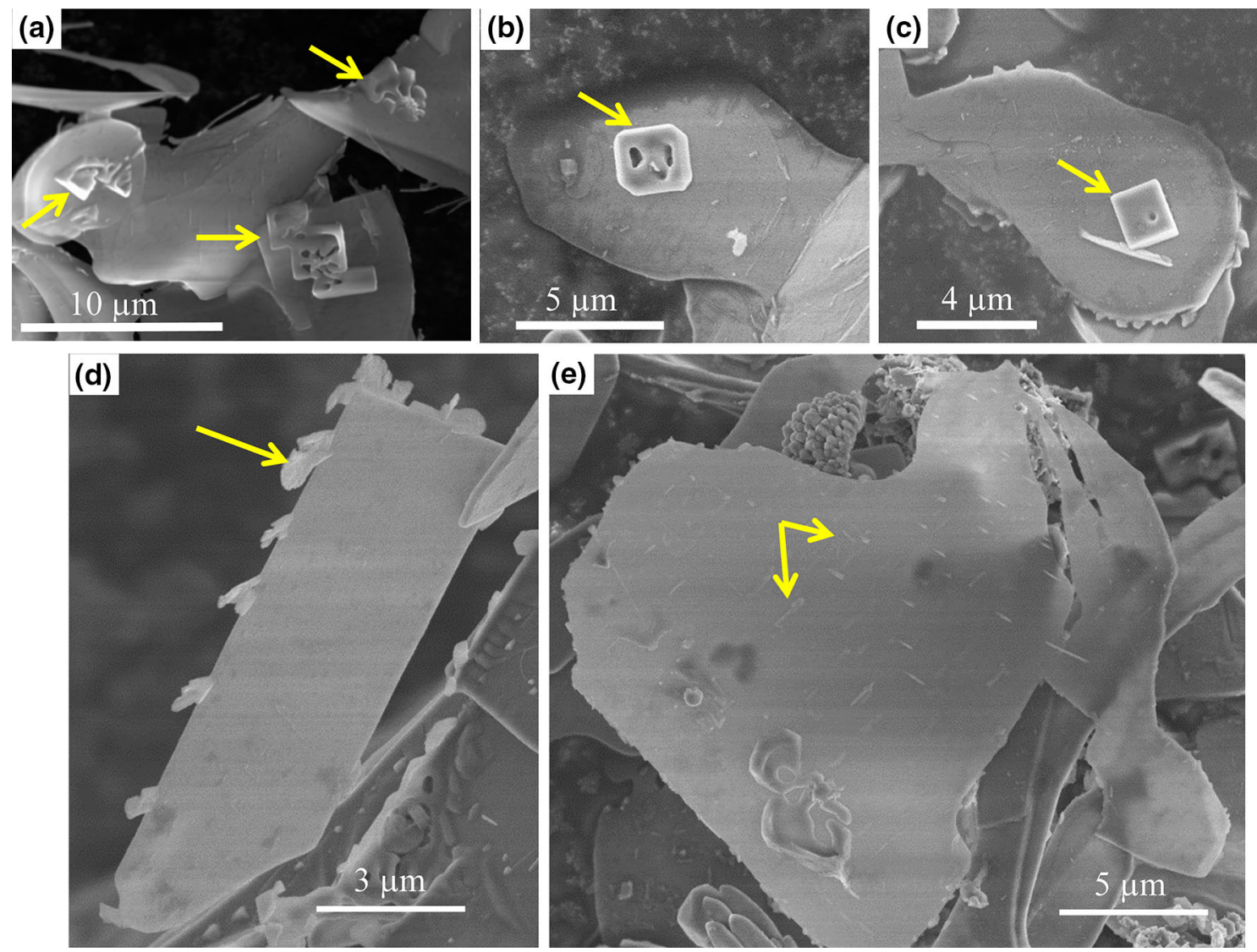

Fig. 11-SE SEM images of the extracted particles showing association of Mg_Si rich particles (arrowed) with $\beta$-AlFeSi.

region. Therefore, there is a stochastic, or statistical, aspect to the nucleation of AlFeSi-based IMCs, depending on the chemical and physical conditions within the final, isolated solute-rich films around evolving dendrites. Even under exactly the same cooling conditions, some films may favor $\alpha_{\mathrm{c}}$-AlFeSi because of the particular local chemistry, or presence of un-used grain refiners (Figure 16), oxides or other inclusions, etc., while others will favor $\beta$-AlFeSi.

\section{Primary $\alpha$-Al, IMC inter-connectivity and spherical} droplets

All the as-cast grain boundary secondary phases form from solute-rich grain boundary films around $\alpha-\mathrm{Al}$ grains. These films have a complex 3D shape, surrounding the evolving dendrites. The secondary phases form from this film and are able to extend, branch and become highly inter-connected over large distances, many times the cell or dendrite spacing or even grain size (as shown in Figure 15(a)). The IMC particles were comparatively finer and less inter-connected nearer to the billet surface because there was a relatively high grain/liquid surface area per unit volume (smaller microstructural scale) here. Nearer the billet center, for a constant liquid fraction, the channel width must increase because of a decrease in grain/liquid surface area per unit volume, resulting in coarser particles and greater inter-connectivity (Figure 8).
Spherical particles within the grains, such as the examples in Figures 7(b) and 12, form from solute-rich liquid droplets that are formed either by pinching off and isolation of the liquid in the final stages of solidification, or are deposited by solute-rich migrating liquid films around the coarsening dendrites, ${ }^{[34]}$ as shown in Figure 15(a)). Consequently, these spherical droplets were not part of the inter-connected IMC network around grains. The fine structure of these solidified droplets further suggest that these droplets may be subject to relatively large undercoolings before they are able to solidify, at temperatures lower than that of the coarser grain boundary Fe-IMCs eutectic, as illustrated in Figure 15(a).

There were also spherical composites of $\mathrm{Si}$ and Fe-IMC particles, similar to those reported in entrained spherical droplet experiments ${ }^{[33,35]}$ but representing only a minority of the IMC particles examined. It is worth remarking that if $\mathrm{Si}$ and $\mathrm{Fe}$, as inevitable impurities in Al alloys, could be contrived to solidify in increased fractions of these spherical-like particles or clusters, the undermining effects of more usual, extended Fe-rich IMCs on final properties might be reduced.

\section{3. $\mathrm{Mg}_{2} \mathrm{Si}$}

The presence of the type 1 (dendritic-like, octahedral-like and cubic-like) and type 2 (seaweed-like) $\mathrm{Mg}_{2} \mathrm{Si}$ particles on the surface of $\beta$-AlFeSi suggests that they 

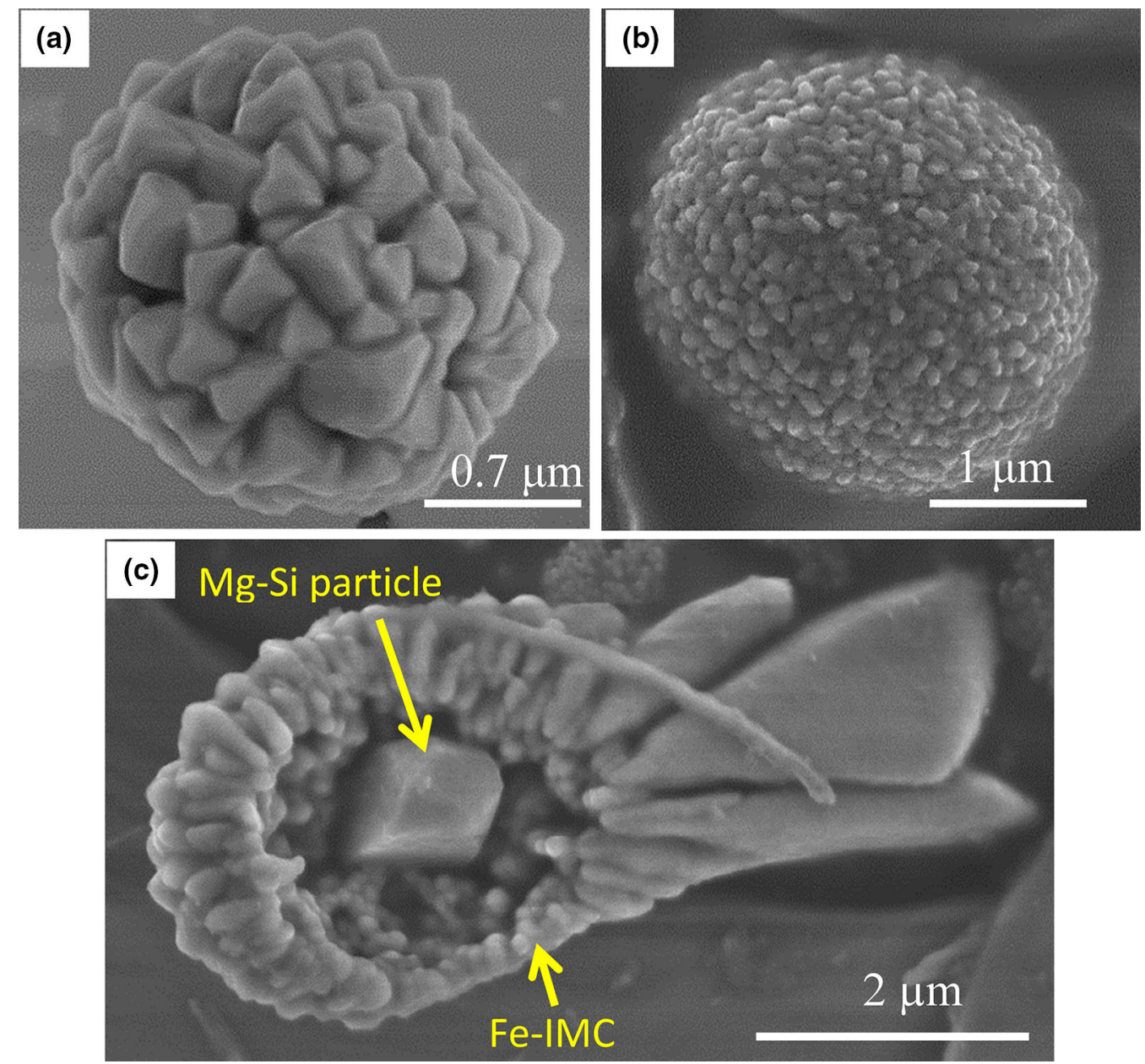

Fig. 12 - SE FEG-SEM images showing a $(a)$ spherical cluster of Fe-IMC particles, $(b)$ spherical cluster of Si-rich particles, and $(c)$ composite of $\mathrm{Mg}_{2} \mathrm{Si}$ and Fe-IMC particles, from the as-cast billet.

formed either by eutectic reaction (7) or directly from liquid by reaction (9), where pre-existing $\beta$-AlFeSi acts as a substrate to nucleate the $\mathrm{Mg}_{2} \mathrm{Si}$, potentially via an intermediate compound (occasionally a Ca-rich signal was recorded by EDX from these regions). Recent transmission electron microscopy (TEM) analysis showed common orientation relationship between $\beta$-AlFeSi and $\mathrm{Mg}_{2} \mathrm{Si}$ in a $6 \mathrm{xxx}$ series Al alloy, ${ }^{[36]}$ which supports the role of $\beta$-AlFeSi as a nucleation substrate.

Once nucleated, further growth of $\mathrm{Mg}_{2} \mathrm{Si}$ depends on factors similar to those already described for the growth of Fe-IMCs, except the residual solute-rich liquid will tend to have ever higher concentrations of $\mathrm{Mg}$ and $\mathrm{Si}$, since $\mathrm{Mg}_{2} \mathrm{Si}$ develops later in the solidification sequence. The octahedral-like (Figure 11(b)) and cubic-like (Figure $11(\mathrm{c})$ ) $\mathrm{Mg}_{2} \mathrm{Si}$ are similar to primary $\mathrm{Mg}_{2} \mathrm{Si}$ in the hyper-eutectic $\mathrm{Al}-\mathrm{Mg}_{2} \mathrm{Si}$ alloys, ${ }^{[37]}$ suggesting they may form directly from solute-rich liquid by reaction (9).

The different morphologies of type $1 \mathrm{Mg}_{2} \mathrm{Si}$ again may arise from the local solidification conditions in the residual liquid "pockets" because of interfacial instability due to the build-up of elements rejected by the growing solid phases (in this case $\mathrm{Al}$ and $\mathrm{Fe}$ may accumulate in the liquid) and physical constraints of growth in the highly restricted film geometry, and in the "holes" inside $\mathrm{Mg}_{2} \mathrm{Si}$ particles (Figure 11(b) and (c)). Type 2 seaweed-like $\mathrm{Mg}_{2} \mathrm{Si}$ along the edges of $\beta$-AlFeSi suggested they formed by eutectic reaction (7), and had a similar morphology to that in an $\mathrm{Al}-\mathrm{Mg}_{2} \mathrm{Si}$ alloy. ${ }^{[38]}$

Finally, the finest-scale $(\sim 0.6 \mu \mathrm{m}) \mathrm{Mg}$ and $\mathrm{Si}$-rich needle-like particles on the surface of $\beta$-AlFeSi are solid state precipitates of $\mathrm{Mg}_{2} \mathrm{Si}$ that formed after solidification at the interface of pre-existing $\beta$-AlFeSi and $\alpha$-Al.

\section{B. Evolution of Fe-IMCs During Homogenization}

The higher proportion of $\alpha_{\mathrm{c}}$-AlFeSi in the homogenized billet arose from the $\beta \rightarrow \alpha_{c}$ transformation. Kuijpers et al. ${ }^{[1]}$ suggested this transformation is solute diffusion controlled, initiated by the $\alpha_{\mathrm{c}}$-AlFeSi nucleation on the basal face of $\beta$-AlFeSi platelets; the $\beta$-AlFeSi then dissolves and $\alpha_{\mathrm{c}}$-AlFeSi grows by consuming released $\mathrm{Fe}, \mathrm{Mn}$ and $\mathrm{Si}$. They also observed an increase in $\mathrm{Mn}$ content in $\alpha_{\mathrm{c}}$-AlFeSi particles after homogenization due to longer diffusion times. ${ }^{[39]}$ In the present study, residual $\beta$-AlFeSi attached to newly transformed $\alpha_{\mathrm{c}}-\mathrm{AlFeSi}$ was not observed and it is estimated that more than 90 pct of the $\beta$-AlFeSi transformed (under these particular homogenization 

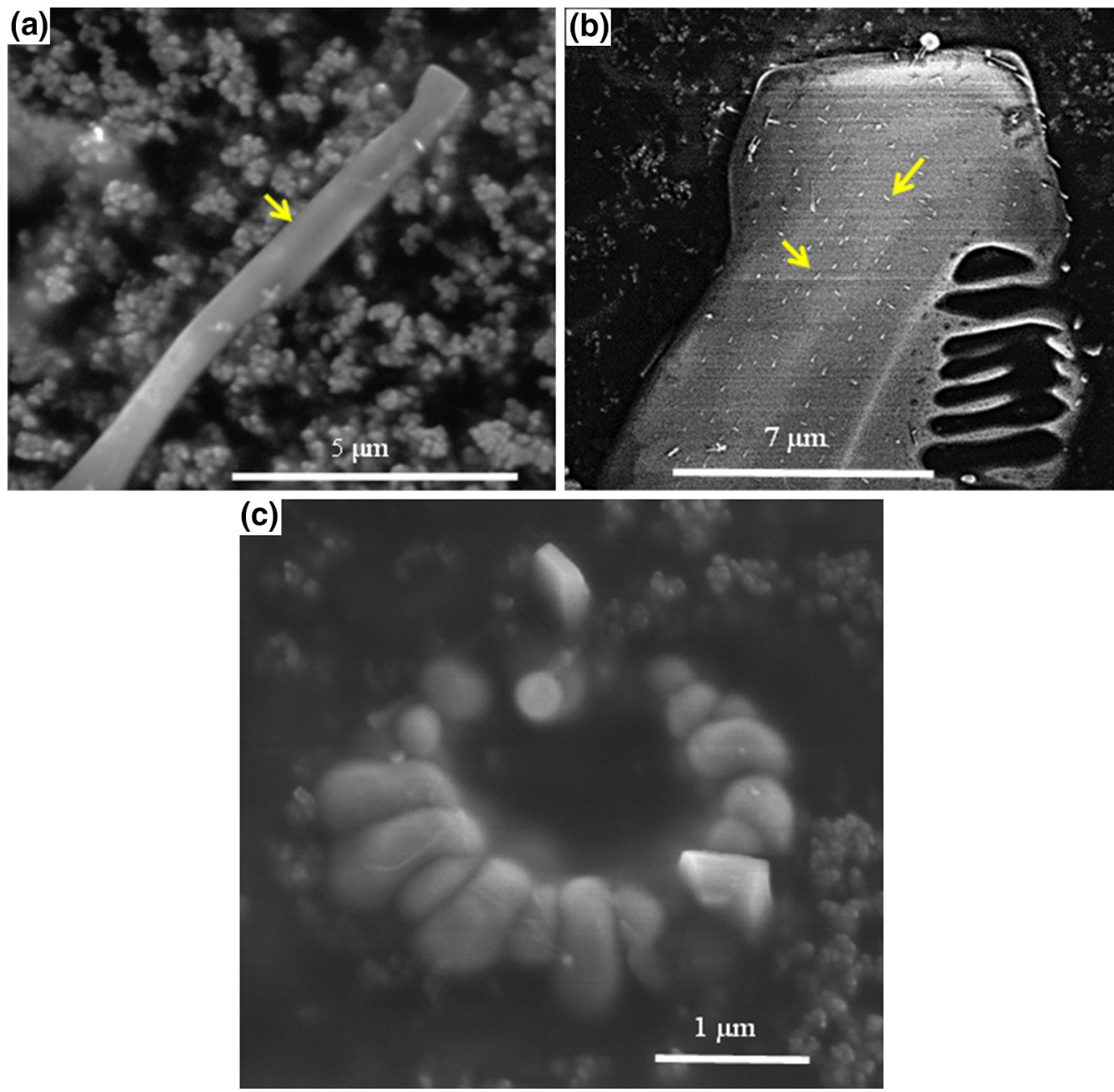

Fig. 13 - SE SEM images of the extracted particles from the homogenized billet showing $(a)$ rod-like $\mathrm{Mg}_{2} \mathrm{Si}$, $(b)$ association of Mg-Si-rich particles with partly degraded $\alpha_{c}-\mathrm{AlFeSi}$, and $(c)$ rosette-like AlFeSi with a hole at the center.

conditions) instead into discrete, fine, cylinder/disk-like $\alpha_{\mathrm{c}}-\mathrm{AlFeSi}$. Further, because disk-like particles were often connected to others e.g. Figure 9(d), more than one $\alpha_{\mathrm{c}}$-AlFeSi crystal may nucleate from the extended area of one $\beta$-AlFeSi platelet.

An attempt was made to investigate if transformed $\alpha_{\mathrm{c}}$-AlFeSi might also nucleate on pre-existing $\alpha_{\mathrm{c}}$-AlFe$\mathrm{Si}$ - since there is presumably good lattice matching and low interfacial energy between them. However, no compelling microstructural evidence could be resolved, and only partly degraded eutectic $\alpha_{\mathrm{c}}$-AlFeSi was evident. It is possible that $\beta$-AlFeSi dissolves in one place and re-precipitates as $\alpha_{c}$-AlFeSi in a different region. If such events were resolvable, in-situ X-ray tomography might be used to study these dynamic effects.

Figure 14 suggests that as-cast $\mathrm{Mg}_{2} \mathrm{Si}$ formed due to non-equilibrium solute segregation to the liquid during solidification and should dissolve more readily than Fe-IMCs during re-heating and isothermal homogenization. A previous in-situ hot-stage investigation ${ }^{[28]}$ on a 6xxx series $\mathrm{Al}$ alloy showed $\mathrm{Mg}_{2} \mathrm{Si}$ particles that were not in contact with Fe-IMCs dissolved first at a lower temperature followed by the particles that were attached to Fe-IMCs. Thus, the dissolution of $\mathrm{Mg}_{2} \mathrm{Si}$ that is attached to $\beta$-AlFeSi, which was commonly observed will induce a comparatively high local Si concentration, which can be expected to affect the kinetics of the $\beta \rightarrow \alpha$ transformation, and perhaps the transformation mechanism itself.

The relatively coarse, equiaxed $\mathrm{Mg}_{2} \mathrm{Si}$ at grain boundaries suggests that some eutectic $\mathrm{Mg}_{2} \mathrm{Si}$ does not dissolve but firstly tends to spheriodise to reduce the interfacial area. ${ }^{[40,41]}$

Because of the dissolution and degradation of grain boundary secondary phases, mainly Fe-IMCs, IMC inter-connectivity was also notably reduced after homogenization (Figure 8(c)), with inter-connectivity only maintained by those particles that retained the larger petals around primary $\alpha-\mathrm{Al}$ grains, as shown in Figure 15(b). Similarly the platelet-like inter-connected $\beta$-AlFeSi breaks into fine disk-like particles during the $\beta$-AlFeSi to $\alpha_{\mathrm{c}}$-AlFeSi transformation leaving finer disk-like particles around grains, as also shown in Figure 15(b). Fe-IMCs formed from spherical droplets inside primary Al persist after homogenization, but the as-solidified $\mathrm{Mg}_{2} \mathrm{Si}$ or $\mathrm{Si}$ is dissolved. 


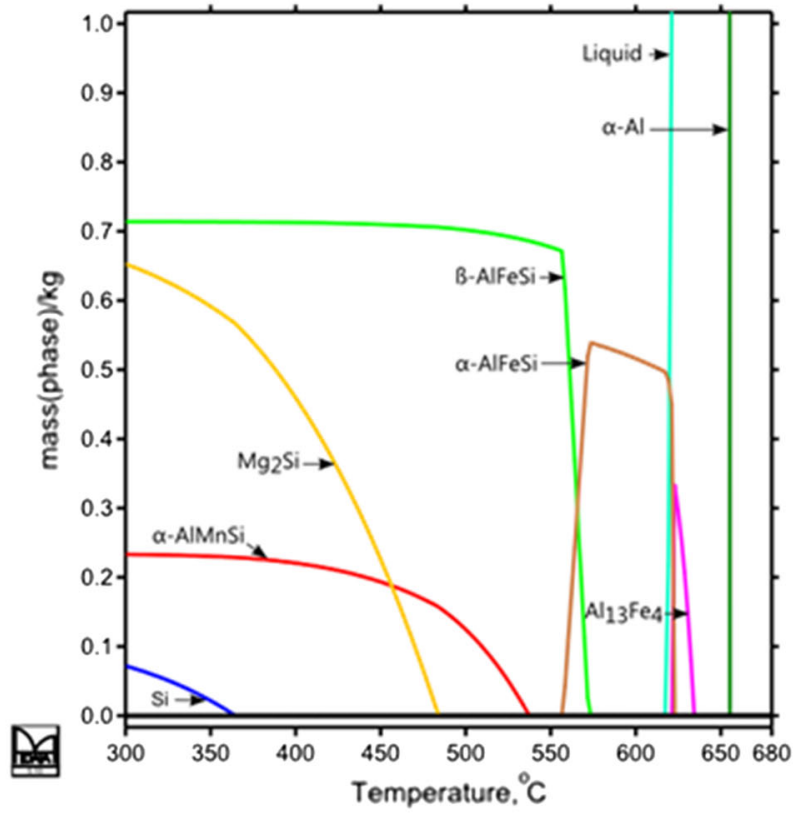

(a)

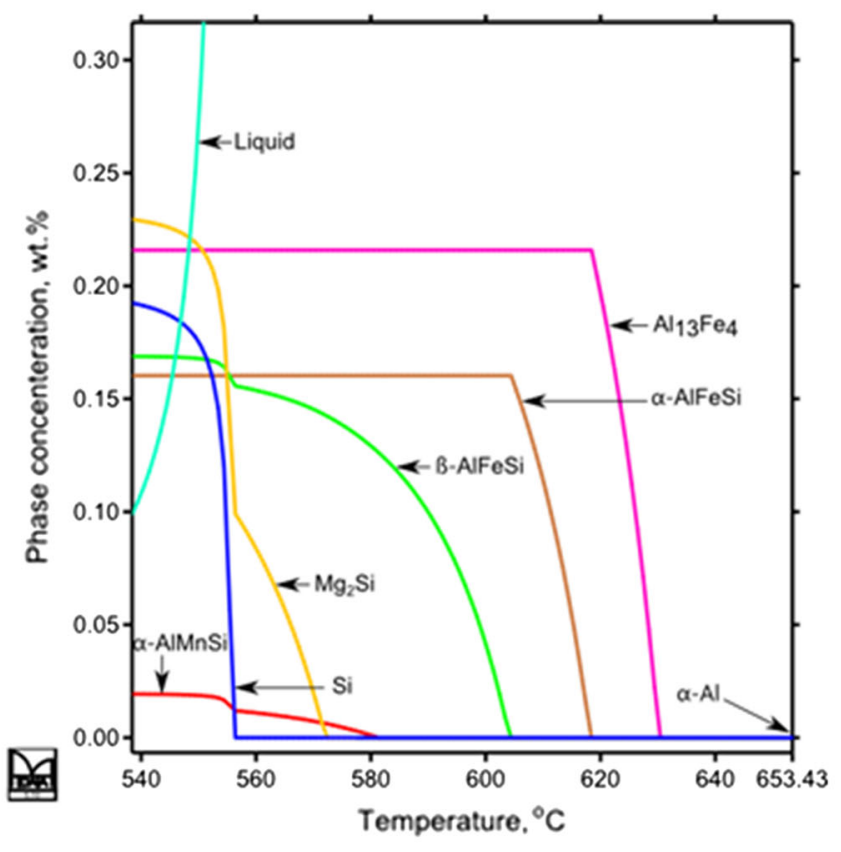

(b)

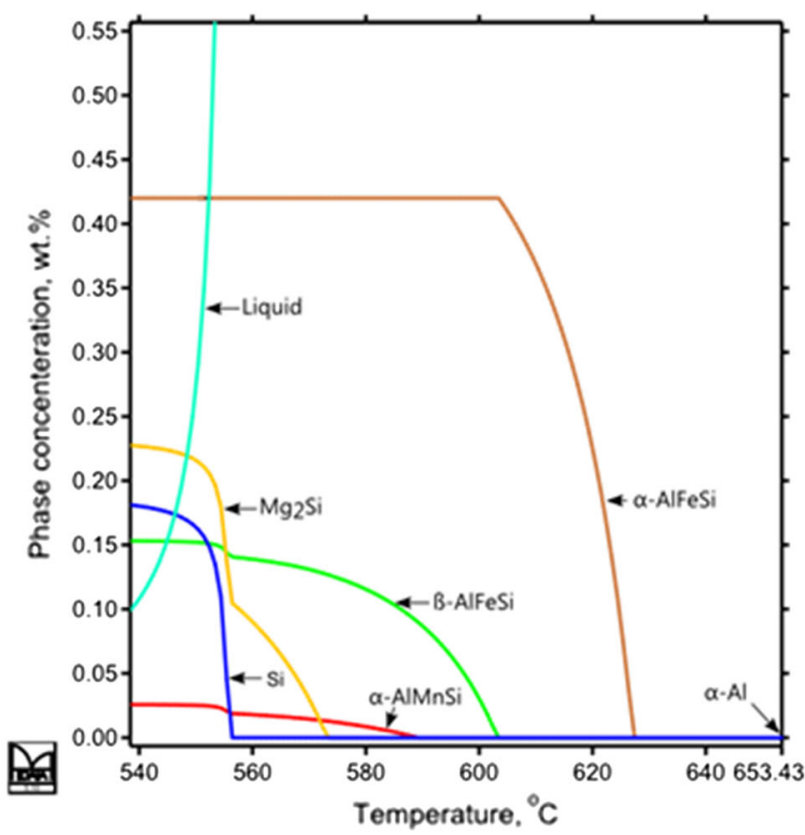

(c)

Fig. 14 -Thermodynamic calculations of phase fraction in alloy 6063, assuming $(a)$ equilibrium, and $(b, c)$ Scheil solidification conditions. Where (c) is Scheil simulation performed without $\mathrm{Al}_{13} \mathrm{Fe}_{4}$.

Based on these insights, summarized schematically in the Figure 15, it is suggested that because $\beta$ transformation to $\alpha_{c}$ leads to a dramatic reduction in inter-connectivity, having a relatively high $\beta$-AlFeSi and spherical Fe-IMCs fraction in the solidified billet can be advantageous as it will result in fine, less connected $\alpha_{\mathrm{c}}$-AlFeSi particles after homogenization. A high fraction of inter-connected $\alpha_{\mathrm{c}}$-AlFeSi in the as-cast billet is harder to break-up (more thermodynamically stable), requiring longer homogenization temperatures and times. So long as the $\beta$ to $\alpha_{\mathrm{c}} \mathrm{AlFeSi}$ transformation is completed, finer intermetallic particles in the billet before downstream deformation process will improve both the deformation efficiency and final property of the product. ${ }^{[15,18]}$ 

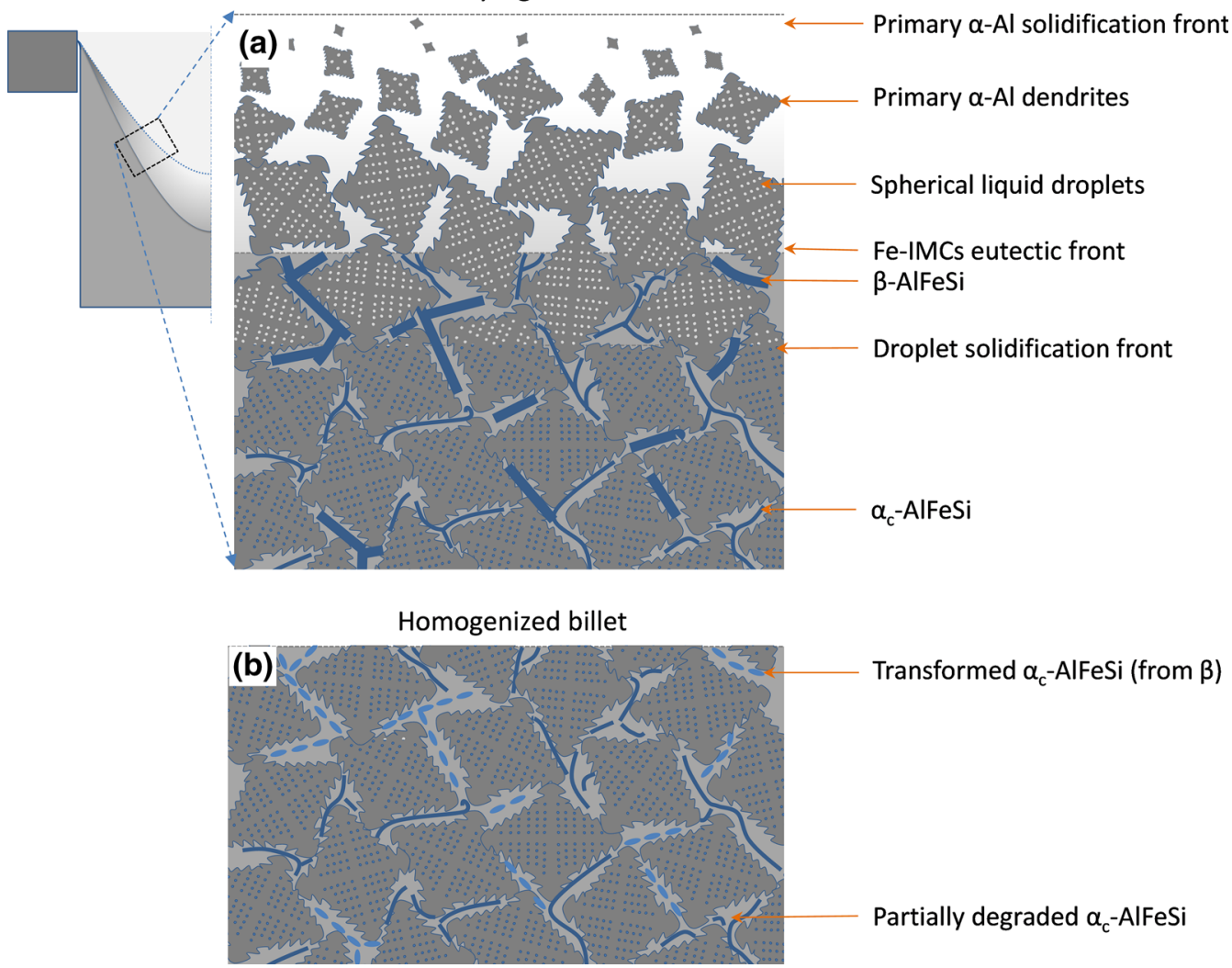

Fig. 15-Schematic representation of the (a) solidification sequence in the 6063 billet during DC casting and (b) the evolution of the microstructure during the homogenization heat treatment.
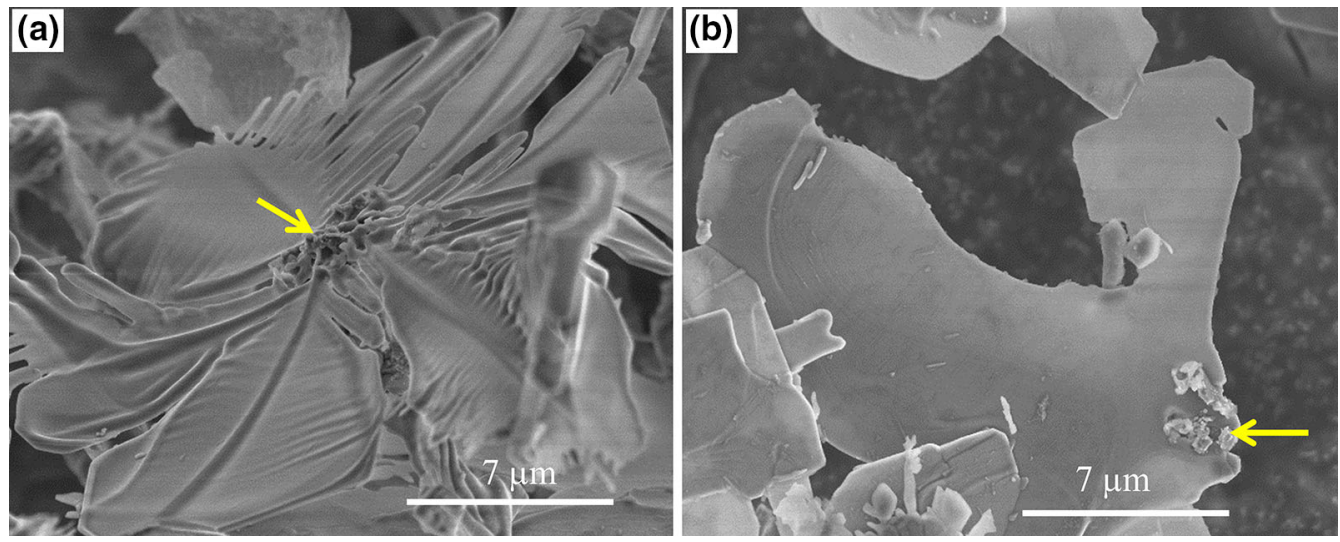

Fig. 16 - SE FEG-SEM images of extracted particles from the as-cast billet with Ti-rich particles (arrowed) associated with $(a) \alpha_{\mathrm{c}}$-AlFeSi and $(b)$ $\beta$-AlFeSi.

\section{CONCLUSIONS}

The as-cast and homogenized microstructure of a DC cast grain-refined $6063 \mathrm{Al}$ alloy was studied across the billet cross section. The primary Al grain size, dendritic arm spacing (DAS), and secondary phase particle size increased from the billet edge to the center of the as-cast billet. When the grain size reduced, the Fe-IMC inter-connectivity also reduced, and vice-versa. Fe was present as majority $\alpha_{c}-\mathrm{AlFeSi}$ and minority $\beta$-AlFeSi IMCs in the as-cast billet, and their relative proportions were not sensitive to position. $\beta$-AlFeSi nucleated $\mathrm{Mg}_{2} \mathrm{Si}$ during solidification, and there were additional solidified spherical droplets of further Fe-IMCs as well as $\mathrm{Mg}_{2} \mathrm{Si}$, $\mathrm{Si}$ and composite particulates within primary $\alpha$-Al grains.

The homogenized billet showed little grain/dendrite coarsening and a marked elimination of inter-dendritic secondary phases. The Fe-IMC inter-connectivity was reduced everywhere, most markedly at the billet surface. Of the other as-cast particles, only spherical-like Fe-IMCs 
persisted within the $\alpha$-Al grains after homogenization. Overall, the results showed that while homogenization treatments are effective, nonetheless the initial as-cast microstructure, which is influenced by the solidification conditions, exerted a strong influence on the final homogenized microstructure, affecting the size, morphology, type, $\beta$ to $\alpha$ transformation rate and inter-connectivity of the various IMCs.

\section{ACKNOWLEDGMENTS}

The authors acknowledge the financial support of the UK Engineering and Physical Science Research Council (EPSRC Grant: Centre for Innovative Manufacturing Research on Liquid Metal Engineering, EP/ $\mathrm{H} 026177 / 1)$ and SAPA, UK.

\section{OPEN ACCESS}

This article is distributed under the terms of the Creative Commons Attribution 4.0 International License (http://creativecommons.org/licenses/by/4.0/), which permits unrestricted use, distribution, and reproduction in any medium, provided you give appropriate credit to the original author(s) and the source, provide a link to the Creative Commons license, and indicate if changes were made.

\section{REFERENCES}

1. O. Reiso: Mater. Forum, 2004, vol. 28, pp. 32-46.

2. C.M. Allen, K.A.Q. O'Reilly, B. Cantor, and P.V. Evans: Prog. Mater. Sci., 1998, vol. 43, pp. 89-170.

3. H. Zhu, M.J. Couper, and A.K. Dahle: JOM, 2011, vol. 63, pp. 66-71.

4. L. Sweet, S.M. Zhu, S.X. Gao, J.A. Taylor, and M.A. Easton: Metall. Mater. Trans. A, 2011, vol. 42A, pp. 1737-49.

5. S. Onurlu and A. Tekin: J. Mater. Sci., 1994, vol. 23, pp. 1652-55.

6. S. Zajac, B.B. Hutchinson, A.A. Johansson, and L.Q.L.-O. Gullman: Mater. Sci. Technol., 1994, vol. 10, pp. 323-33.

7. M.H. Mulazimoglu, A. Zaluska, J.E. Gruzleski, and F. Paray: Metall. Mater. Trans. A, 1996, vol. 27A, pp. 929-36.

8. G. Sha, K.A.Q. O'Reilly, B. Cantor, J. Worth, and R. Hamerton: Mater. Sci. Eng. A, 2001, vols. 304-306, pp. 612-16.

9. S. Kumar, P.S. Grant, and K.A.Q. O'Reilly: Trans. Indian Inst. Met., 2012, vol. 65, pp. 553-57.

10. H. Tanihata, T. Sugawara, K. Matsuda, and S. Ikeno: J. Mater. Sci., 1999, vol. 34, pp. 1205-10.

11. N.C.W. Kuijpers, F.J. Vermolen, K. Vuik, and S. Van Der Zwaag: Mater. Trans., 2003, vol. 44, pp. 1448-56.
12. J. Sarkar, T.R.G. Kutty, D.S. Wilkinson, J.D. Embury, and D.J. Lloyd: Mater. Sci. Eng. A, 2004, vol. 369, pp. 258-66.

13. Y. Birol: J. Mater. Process. Technol., 2004, vol. 148, pp. 250-58.

14. K.B.S. Couto, S.R. Claves, W.H. Van Geertruyden, W.Z. Misiolek, and M. Goncalves: Mater. Sci. Technol., 2005, vol. 21, pp. 263-68.

15. S. Kumar, N.H. Babu, G.M. Scamans, Z. Fan, and K.A.Q. O'Reilly: Metall. Mater. Trans. A, 2014, vol. 45, pp. 2842-54.

16. J. Asensio-Lozano, B. Suárez-Peña, and G.F.V. Voort: Materials, 2014, vol. 7, pp. 4224-42.

17. G.I. Eskin and I.N. Friedlyander: Met. Sci. Heat Treat., 1962, vol. 4, pp. 154-57.

18. S. Kumar, N.H. Babu, G.M. Scamans, and Z. Fan: Metall. Mat. Trans. A, 2011, vol. 42A, pp. 3141-49.

19. J.B. Patel, H.T. Li, M.X. Xia, S. Jones, S. Kumar, K. O'Reilly, and Z. Fan: Mater. Sci. Forum, 2014, pp. 149-54.

20. E. Liotti, A. Lui, R. Vincent, S. Kumar, Z. Guo, T. Connolley, I.P. Dolbnya, M. Hart, L. Arnberg, R.H. Mathiesen, and P.S. Grant: Acta. Mater., 2014, vol. 70, pp. 228-39.

21. C. Hsu, K.A.Q. O'Reilly, B. Cantor, and P.V. Evans: Procedings of the 4th Decennial International Conference on Solidification Processing. (1997).

22. A. Verma, S. Kumar, P.S. Grant, and K.A.Q. O'Reilly: J. Alloys Compd., 2013, vol. 555, pp. 274-82.

23. D.G. Eskin: Physical Metallurgy of Direct Chill Casting of Aluminum Alloys, CRC Press/Taylor \& Francis, Boca Raton, 2008.

24. T. Smith, K. O'Reilly, S. Kumar, and I. Stone: Metall. Mater. Trans. A, 2013, vol. 44A, pp. 4866-71.

25. H. Westengen: Z. Metallkd., 1982, vol. 73, pp. 360-68.

26. D.G. Eskin, J. Zuidema, V.I. Savran, and L. Katgerman: Mater. Sci. Eng. A, 2004, vol. 384, pp. 232-44.

27. Standard test procedure for aluminum alloy grain refiners, AA TP-1, The Aluminium Association, 1990.

28. G. Sha: Department of Materials, University of Oxford, Oxford, 2001.

29. C. Hsu: Department of Materials, University of Oxford, Oxford, 1999.

30. G. Sha, K.A.Q. O'Reilly, B. Cantor, J.M. Titchmarsh, and R.G. Hamerton: Acta. Mater., 2003, vol. 51, pp. 1883-97.

31. L.F. Mondolfo: Aluminum Alloys: Structure and Properties, Butterworths, Boston, 1976.

32. L. Bäckerud, E. Król, and J. Tamminen: Solidification Characteristics of Aluminium Alloys, vol. 1, 1986.

33. C. Hsu, K.A.Q. O'Reilly, B. Cantor, and R. Hamerton: Mater. Sci. Eng. A, 2001, vols. 304-306, pp. 119-24.

34. E.D. Manson-Whitton, I.C. Stone, J.R. Jones, P.S. Grant, and B. Cantor: Acta. Mater., 2002, vol. 50, pp. 2517-35.

35. C.M. Allen, K.A.Q. O'Reilly, P.V. Evans, and B. Cantor: Acta. Mater., 1999, vol. 47, pp. 4387-403.

36. J.H. Li, A. Wimmer, G. Dehm, and P. Schumacher: Philos. Mag., 2014 , vol. 94 , pp. $830-46$.

37. C. Li, Y.Y. Wu, H. Li, and X.F. Liu: Acta. Mater., 2011, vol. 59, pp. $1058-67$.

38. C. Li, Y. Wu, H. Li, and X. Liu: J. Alloys Compd., 2009, vol. 477, pp. $212-16$.

39. N.C.W. Kuijpers, W.H. Kool, P.T.G. Koenis, K.E. Nilsen, I. Todd, and S. van der Zwaag: Mater. Char., 2003, vol. 49, pp. 409-20.

40. M. Usta, M.E. Glicksman, and R.N. Wright: Metall. Mater. Trans. A, 2004, vol. 35A, pp. 435-38.

41. G.V. Voort, B. Suárez-Peña, and J. Asensio-Lozano: Microsc. Microanal., 2013, vol. 19, pp. 276-84. 